\title{
Controlling Protein Surface Orientation by Strategic Placement of Oligo-Histidine Tags
}

Dorothee Wasserberg, ${ }^{\dagger, \ddagger, \S, \# ~ J o r d i ~ C a b a n a s-D a n e ́ s, ~}{ }^{\dagger, \ddagger, \#}$ Jord Prangsma, ${ }^{\S}$ Shane O’Mahony, ${ }^{\perp}$

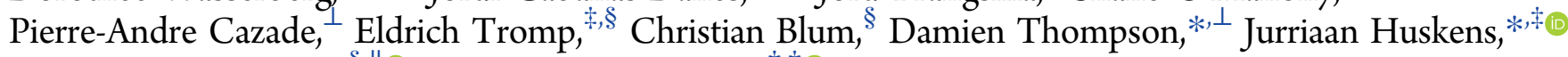

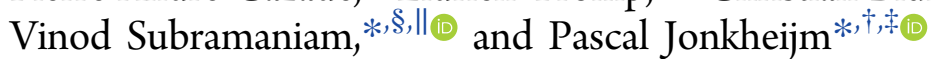

${ }^{\dagger}$ Bioinspired Molecular Engineering Laboratory, MIRA Biomedical Technology and Technical Medicine Institute, ${ }^{\ddagger}$ Molecular nanoFabrication Group, MESA+ Institute for Nanotechnology, and ${ }^{\S}$ Nanobiophysics Group, MESA+ Institute for Nanotechnology, and MIRA Biomedical Technology and Technical Medicine Institute, University of Twente, P.O. Box 217, 7500 AE Enschede, The Netherlands

${ }^{\perp}$ Department of Physics, Bernal Institute, University of Limerick, Limerick V94 T9PX, Ireland

"Free University of Amsterdam, De Boelelaan 1105, $1081 \mathrm{HV}$ Amsterdam, The Netherlands

\section{Supporting Information}

ABSTRACT: We report oriented immobilization of proteins using the standard hexahistidine $\left(\mathrm{His}_{6}\right)-\mathrm{Ni}^{2+}$ :NTA (nitrilotriacetic acid) methodology, which we systematically tuned to give control of surface coverage. Fluorescence microscopy and surface plasmon resonance measurements of self-assembled monolayers (SAMs) of red fluorescent proteins (TagRFP) showed that binding strength increased
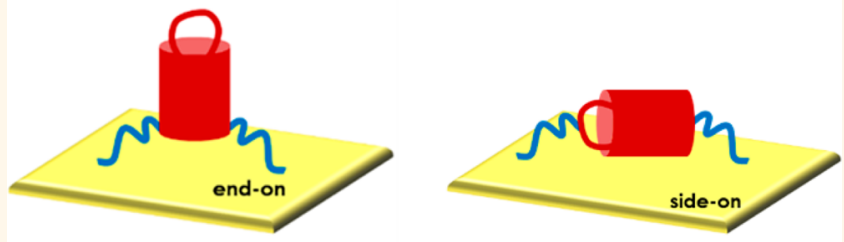
by 1 order of magnitude for each additional $\mathrm{His}_{6}$-tag on the TagRFP proteins. All TagRFP variants with $\mathrm{His}_{6}$-tags located on only one side of the barrel-shaped protein yielded a 1.5 times higher surface coverage compared to variants with $\mathrm{His}_{6}$-tags on opposite sides of the so-called $\beta$-barrel. Timeresolved fluorescence anisotropy measurements supported by polarized infrared spectroscopy verified that the orientation (and thus coverage and functionality) of proteins on surfaces can be controlled by strategic placement of a His ${ }_{6}$-tag on the protein. Molecular dynamics simulations show how the differently tagged proteins reside at the surface in "end-on" and "side-on" orientations with each $\mathrm{His}_{6}$-tag contributing to binding. Also, not every dihistidine subunit in a given His -tag $^{- \text {tan }}$ forms a full coordination bond with the $\mathrm{Ni}^{2+}$ :NTA SAMs, which varied with the position of the His ${ }_{6}$-tag on the protein. At equal valency but different tag positions on the protein, differences in binding were caused by probing for $\mathrm{Ni}^{2+}: \mathrm{NTA}$ moieties and by additional electrostatic interactions between different fractions of the $\beta$-barrel structure and charged NTA moieties. Potential of mean force calculations indicate there is no specific single-protein interaction mode that provides a clear preferential surface orientation, suggesting that the experimentally measured preference for the end-on orientation is a supra-protein, not a single-protein, effect.

KEYWORDS: protein immobilization, multivalency, monolayers, molecular dynamics simulations, self-assembly

P roteins anchored on solid substrates play a crucial role in biomedical, bioanalytical, and biotechnological applications, biomaterials, and nanobiotechnological devices and surfaces. ${ }^{1-9}$ Specific properties of surface-based diagnostic assays and cell culture supports often depend on site-selective attachment of proteins to solid supports. ${ }^{10-12}$ Grafting a suitable binding motif to a specific site on the protein provides control over the orientation of proteins on solid supports, ${ }^{13-16}$ which, unlike nonspecific or non-site-selective anchoring, generates homogeneous surface coverage and, if wellconsidered, easy accessibility to the proteins' active sites. ${ }^{10-12}$ Consequently, different types of bio-orthogonal reactions, both noncovalent and covalent, have been developed to sitespecifically attach proteins to surfaces. ${ }^{10-12,17-31}$ While functional attachment of proteins to solid supports with some control over orientation has been achieved, firm structural evidence of uniformly oriented proteins is lacking. For example, Saavedra and co-workers studied, using emission anisotropy, the distribution of orientations of cytochrome $c$, which were site-selectively and covalently attached to substrates through disulfide bond formation between a single reduced cysteine residue on the proteins and the surface-exposed thiol groups of a self-assembled monolayer $(\mathrm{SAM}) .^{32}$ A broad range $\left(12^{\circ} \pm\right.$ $33^{\circ}$ ) of heme orientations signified a disordered layer with a substantial fraction of nonspecifically adsorbed proteins. ${ }^{32}$

Received: May 26, 2017

Accepted: August 29, 2017

Published: August 29, 2017 
Taking advantage of a lipid bilayer to resist nonspecific protein adsorption yielded more oriented cytochrome $c$ layers $\left(41^{\circ} \pm\right.$ $\left.11^{\circ}\right) .^{33}$ Scoles and co-workers grafted metal-chelating thiols (specifically, nitrilotriacetic acid (NTA)-terminated thiols) into antifouling SAMs to capture hexahistidine ( $\left.\mathrm{His}_{6}\right)$-tagged antibodies with high affinity for specific epitopes on prion proteins. $^{34}$ Oriented immobilization of prion proteins was topographically detected. ${ }^{34}$ Multivalent host-guest interactions have been used by us to immobilize light-harvesting protein LH2 complexes that were engineered with cysteine residues close to the C-terminus of each of the nine $\alpha$-domains of LH2 and functionalized with adamantane guests. ${ }^{35}$ These positions ensured oriented, yet irreversibly bound, protein complexes upon binding to $\beta$-cyclodextrin host surfaces. ${ }^{35}$ In linear arrays of such oriented proteins characteristic energy migration could be observed. ${ }^{36}$ Tampé and co-workers attached a $20 \mathrm{~S}$ proteasome to substrates functionalized with metal-chelating NTA complexes using $\mathrm{His}_{6}$-tags attached (randomly) to only one of the subunits, either the outer $\alpha$ - or inner $\beta$-subunit, of the $20 \mathrm{~S}$ proteasome. ${ }^{37,38}$ Placing $\mathrm{His}_{6}$-tags on the outer $\alpha$ subunits resulted in an end-on orientation of the barrel-shaped enzyme, while $\mathrm{His}_{6}$-tags attached to the inner $\beta$-subunits resulted in side-on immobilization. ${ }^{37,38}$ Proteolytic activity was determined for both orientations of the $20 \mathrm{~S}$ proteasome on the surface and found to differ by a factor of $2 .^{38}$ End-on immobilization of the proteasome demonstrated that one pore is sufficient for substrate entry and product release. ${ }^{38}$ Remarkably, end-on-oriented proteasomes could process only one substrate at a time, while in contrast, the side-onimmobilized proteasome could bind two substrates. ${ }^{38}$ These findings demonstrated clearly that orientational control over the immobilization of proteins influenced their efficiency and functionality. Yet, despite the fact that control over protein orientation and geometry has a strong influence on protein function when immobilized, protein immobilization has not as yet been demonstrated with tunable control over the orientation, binding strength, and reversibility of protein adsorption.

We have previously reported on a covalent disulfide lock between two ferrocenyl (guest)-modified fluorescent proteins to switch from monovalent to divalent interactions with the $\beta$ cyclodextrin $(\beta$-CD) host surface, yielding stable immobilized protein layers with homogeneous orientation. ${ }^{27}$ Here, using multivalency as a design principle, ${ }^{39,40}$ we study controlled immobilization based on a combination of site-directed mutagenesis, surface modification techniques, multivalent numerical models, and molecular simulations. Fluorescent proteins were engineered with $\mathrm{His}_{6}$-tag residues at specific positions on the proteins (Chart 1). These strategic positions ensured unique orientations and properties of proteins upon binding to $\mathrm{Ni}^{2+}$ :NTA surfaces. Given the widespread use of $\mathrm{His}_{6}$-tag technology in protein diagnostics, isolation, surfacebased devices, and bionanostructures, the results of this investigation should be of general interest. ${ }^{21,41-55}$ Isothermal calorimetry and stop-flow fluorescence studies in solution by Tampé and co-workers show that individual $\mathrm{Ni}^{2+}$ :NTA-His complexes (forming one coordination pair) are of low affinity $\left(K_{\mathrm{d}}=14 \mu \mathrm{M}\right)$, two coordination pairs in $\mathrm{Ni}^{2+}$ :NTA-His 4 complexes are of moderate affinity $\left(K_{\mathrm{d}}=0.27 \mu \mathrm{M}\right)$, while high affinity $\left(K_{\mathrm{d}}=20 \mathrm{nM}\right)$ could be reached by incorporating three NTA moieties into a single multivalent chelator entity (forming three coordination pairs in $\mathrm{Ni}^{2+}$ :NTA-His 6 complexes). ${ }^{56}$ While not all of these values have been validated on
Chart 1. Schematic representation of the five TagRFP variants $(0 \mathrm{H}, 1 \mathrm{H}, 2 \mathrm{H}, 1+1 \mathrm{H}, 2+1 \mathrm{H})$ used in this study with different numbers of $\mathrm{His}_{6}$-tags located at the $\mathrm{N}$ - and/or $\mathrm{C}$-terminus and/or at the serine-to-cysteine mutation site (S128C). End-on and side-on oriented TagRFP binding scenarios and the complexation of $\mathrm{Ni}^{2+}$ :NTA SAMs (for preparation see Scheme $\mathrm{S} 1$ ) by a $\mathrm{His}_{6}$-tag are shown.
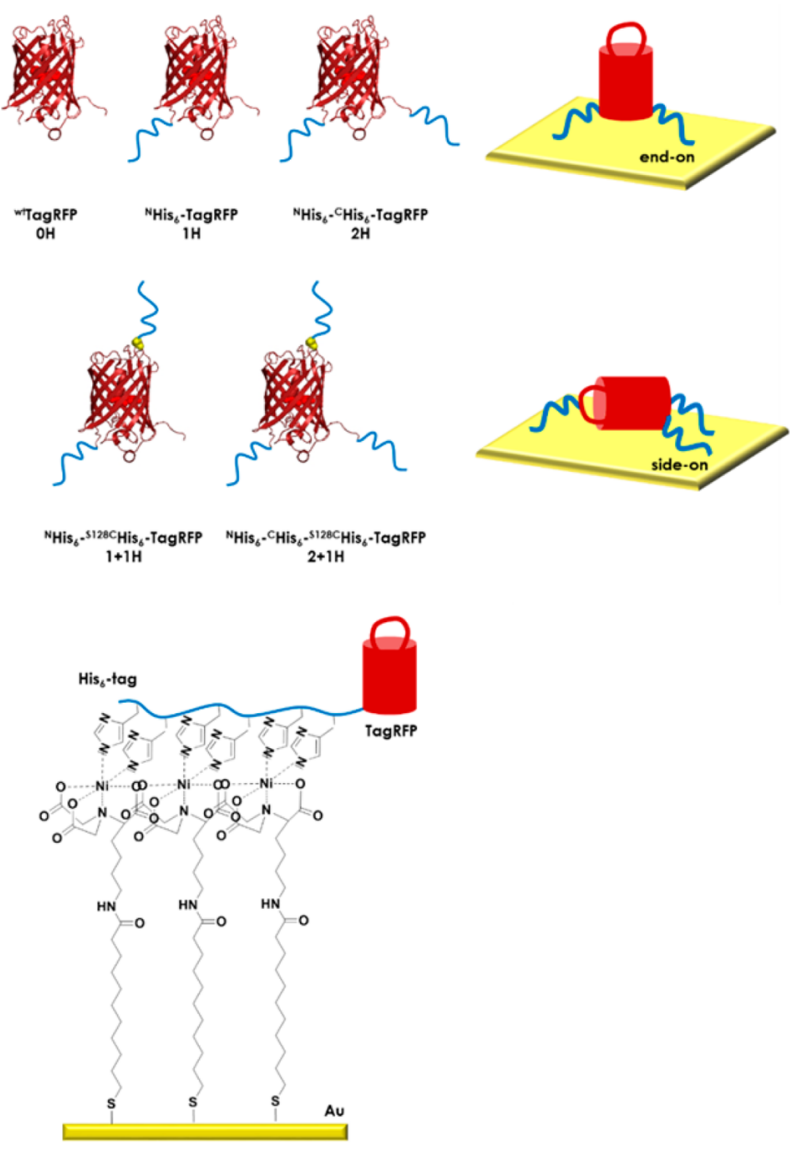

surfaces, Szoka and co-workers found nanomolar affinities for immobilizing $\mathrm{His}_{6}$-tagged proteins on trivalent NTA chelators on gold chips, which depended on linker length and surface density of the chelator. ${ }^{62}$ Complex formation remains reversible upon addition of competitive binding moieties, which has been demonstrated in several other protein immobilization studies. $^{21,47,48,55-64}$ On surfaces, dissociation of longer His Ho $_{10}$-tagged proteins could be inhibited by accumulated "patches" of multivalent NTA entities on surfaces. ${ }^{58,59}$ Analogously, we have established multivalent $\mathrm{Ni}^{2+}$ :NTA surfaces anchored to $\beta$ cyclodextrin host surfaces employing a divalent adamantylNTA moiety, yet the binding affinities were estimated to be markedly lower when compared to solution data, due to incomplete complex formation. ${ }^{55,63}$ More precisely, on such $\beta$ cyclodextrin-anchored $\mathrm{Ni}^{2+}$ :NTA surfaces about $60 \%$ of the $\mathrm{His}_{6}$-tagged proteins formed three coordination pairs with an estimated affinity of $K_{\mathrm{d}}=1 \mu \mathrm{M}$ taking advantage of the spatial arrangement of NTA ligands on the host surface, while the remaining $40 \%$ formed only two coordination pairs with an estimated affinity of $K_{\mathrm{d}}=10 \mu \mathrm{M} .^{55,63}$ Rant and co-workers employed an electric field to switch between horizontally and vertically oriented $\mathrm{His}_{6}$-tagged proteins on the $\mathrm{Ni}^{2+}$ :NTA substrate. ${ }^{65}$ They also demonstrated that binding characteristics of $\mathrm{His}_{6}$-tagged proteins are largely affected by additional 
interactions in the local chemical environment between the protein and surface, yielding $K_{\mathrm{D}}$ values ranging between $1 \mu \mathrm{M}$ and $1 \mathrm{nM}$. $^{65}$

Here, we manipulate the orientation of histidine-tagged proteins on $\mathrm{Ni}^{2+}$ :NTA functional surfaces without resorting to other substrate-protein interactions ${ }^{55,63}$ or external forces. ${ }^{65}$ The molecular-scale details of the protein-surface interface were monitored using fluorescence microscopy, IR spectroscopy, surface plasmon resonance, and time-resolved fluorescence anisotropy techniques supported by equilibrium and steered molecular dynamics computer simulations. Our results demonstrate that the orientation of proteins on surfaces can be controlled by strategic placement of $\mathrm{His}_{6}$-tags on the protein.

\section{RESULTS AND DISCUSSION}

Engineering Protein Variants. The protein we employed is a red fluorescent protein (RFP), more specifically, an orange, monomeric variant of an RFP from the sea anemone Entacmaea quadricolor, TagRFP, ${ }^{66}$ and we trace the proteins at the surface using (time-resolved, polarized) spectroscopy, fluorescence microscopy, and surface plasmon resonance. Recombinant variants of TagRFP were made containing between zero and three $\mathrm{His}_{6}$-tags at different positions on the protein (Chart 1 and Methods). His $_{6}$-tags were introduced at either one or both of the termini by cloning and/or after site-selective mutagenesis to create a single accessible cysteine residue by orthogonal conjugation. The studied proteins included a (wild-type)

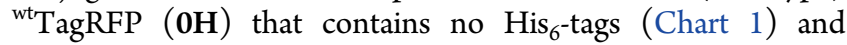
two mutants of ${ }^{\text {wt }}$ TagRFP each with native cysteines $\mathrm{C} 114$ and C222 mutated to serine ( $\mathrm{C} 114 \mathrm{~S}$ and $\mathrm{C} 222 \mathrm{~S}$ ) to remove solvent-accessible cysteine residues. Both mutants have either one or two $\mathrm{His}_{6}$-tags, named ${ }^{\mathrm{N}} \mathrm{His}_{6}$-TagRFP (1H) and ${ }^{\mathrm{N}} \mathrm{His}_{6}{ }^{-}{ }^{\mathrm{C}} \mathrm{His}_{6}$-TagRFP (2H), respectively. The N- and C-termini in TagRFP are located at the base of its cylindrical structure, the so-called $\beta$-barrel, which places the two $\mathrm{His}_{6}$-tags of $2 \mathbf{H}$ at the same end of the $\beta$-barrel (Chart 1). Furthermore, two more mutants with two and three $\mathrm{His}_{6}$-tags were made, each containing three mutations, i.e., again $\mathrm{C} 114 \mathrm{~S}$ and $\mathrm{C} 222 \mathrm{~S}$ but now also serine $\mathrm{S} 128$ are mutated into a cysteine (S128C) to give a single, solvent-accessible cysteine residue. These two mutants were conjugated with a maleimide caproic acid modified hexahistidine tag $\left(\right.$ mic- $\left.-\mathrm{His}_{6}\right)$. The conjugates were named ${ }^{\mathrm{N}} \mathrm{His}_{6^{-}}{ }^{\mathrm{S}^{128} \mathrm{C}} \mathrm{His}_{6^{-}}$TagRFP $(\mathbf{1}+\mathbf{1 H})$ and ${ }^{\mathrm{N}} \mathrm{Hi}^{-}$ $\mathrm{s}_{6}{ }^{-} \mathrm{CHis}_{6}{ }^{\mathrm{S}}{ }^{\mathrm{S} 128 \mathrm{C}} \mathrm{His}_{6}$-TagRFP $(\mathbf{2}+\mathbf{1 H})$. The single accessible cysteine at position 128 is located in a flexible loop on the side of the $\beta$-barrel opposite the $\mathrm{N}$ - and $\mathrm{C}$-termini. This means that conjugates $\mathbf{1}+\mathbf{1 H}$ and $\mathbf{2}+\mathbf{1 H}$ have the second or, respectively, the third of their $\mathrm{His}_{6}$-tags situated at the opposite end of their $\beta$-barrels with regard to the first or, respectively, the first two His $_{6}$-tags (Chart 1 and Methods). The steady-state and timeresolved spectroscopic properties of all mutants and conjugates were verified to match those of the wild-type TagRFP (Table S1).

Demonstration of Reversible Binding of Protein Variants. For a qualitative assessment of the stability and reversibility of the immobilization, TagRFP variants $\mathbf{1 H}, \mathbf{2 H}, \mathbf{1}$ $+\mathbf{1 H}$, and $\mathbf{2}+\mathbf{1 H}$ were immobilized on bifunctional line patterns made by nanoimprint lithography (NIL; Methods and Scheme S2). Patterns consisted of wide $\mathrm{Ni}^{2+}$ :NTA-terminated lines (varying width) and narrower $(5 \mu \mathrm{m}$ wide) poly(ethylene oxide) (PEG)-terminated lines. These patterned surfaces were incubated with solutions of the TagRFP variants for $30 \mathrm{~min}$. After washing, no distinctive patterns were observed. By contrast, extended washing for $12 \mathrm{~h}$ in phosphate-buffered saline (PBS) with 5\% Tween (PBST) yielded clean backgrounds and specifically immobilized proteins. Fluorescence micrographs (Figure 1) were recorded, and fluorescence

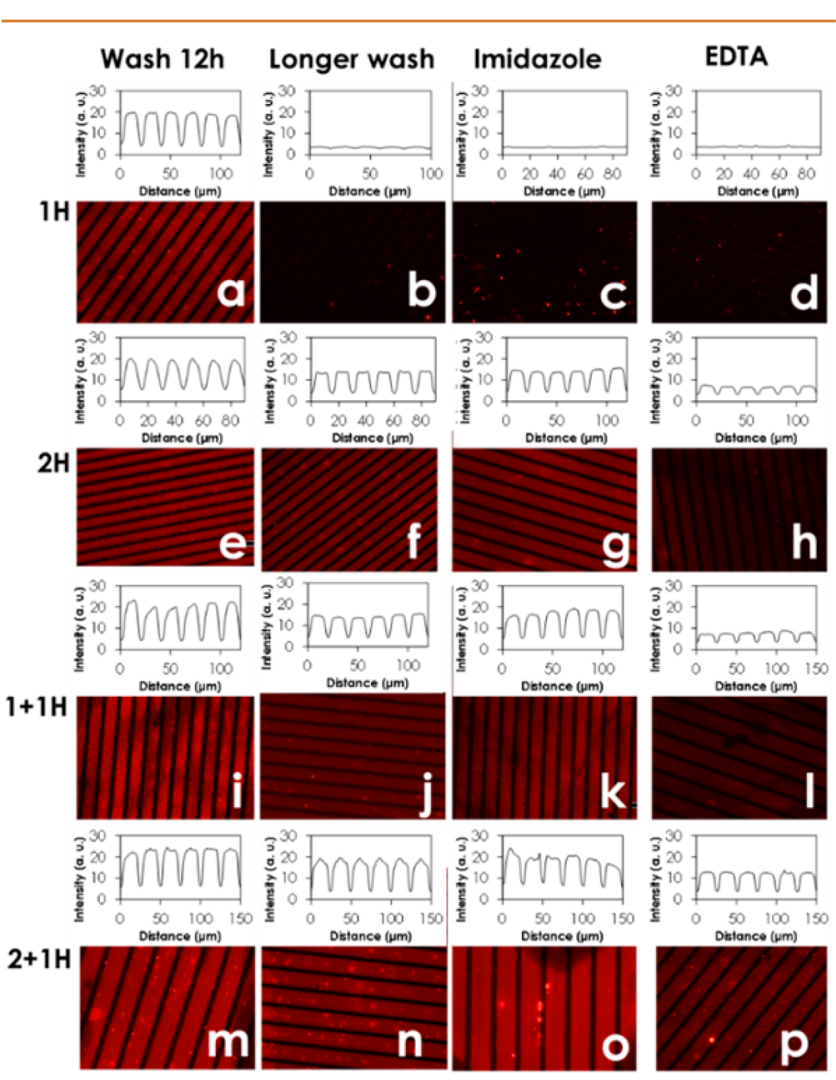

Figure 1. Fluorescence micrographs of NIL-patterned substrates with $\mathrm{Ni}^{2+}$ :NTA- (broad lines) and PEG-terminated regions (narrow lines) after incubation with $1 \mathrm{H}(\mathrm{a}-\mathrm{d}), 2 \mathrm{H}(\mathrm{e}-\mathrm{h}), 1+1 \mathrm{H}(\mathrm{i}-\mathrm{l})$, and $2+1 \mathrm{H}(\mathrm{m}-\mathrm{p})$ and subsequent washing with PBS containing $5 \%$ Tween for $12 \mathrm{~h}(\mathrm{a}, \mathrm{e}, \mathrm{i}, \mathrm{m})$, for $48 \mathrm{~h}(\mathrm{~b}, \mathrm{f}, \mathrm{j}, \mathrm{n})$, and for $2 \mathrm{~h}$ with PBS containing $5 \%$ Tween saturated with imidazole $(c, g, k, o)$ or EDTA (d, h, l, p), and, subsequently, with PBS containing 5\% Tween for $12 \mathrm{~h}$ (c, d, g, h, l, k, p, o). Insets show the corresponding intensity profiles perpendicular to the pattern. Imaging parameters, such as the exposure time of $2 \mathrm{~s}$, were kept constant for all measurements.

intensity profiles measured across the lines (insets Figure 1). All variants were bound to $\mathrm{Ni}^{2+}$ :NTA regions, and only faint signatures of nonspecific binding to the proteophobic PEGterminated regions were observed, indicating site-selective binding of the $\mathrm{His}_{6}$-tag(s) to $\mathrm{Ni}^{2+}$ :NTA-terminated surfaces. No binding was observed to the entire surface in the case of $\mathbf{0 H}$, indicating the specificity of the binding of the proteins by the $\mathrm{His}_{6}$-tags. No significant differences in fluorescence intensities were observed between the different variants after $12 \mathrm{~h}$ of washing. However, after washing with PBST for $48 \mathrm{~h}$ the $\mathbf{1 H}$ line patterns had vanished (Figure $1 \mathrm{~b}$ ) and $\mathbf{2} \mathbf{H}$ and $\mathbf{1}+$ $\mathbf{1 H}$ patterns showed significantly reduced intensities, while $\mathbf{2}+$ $\mathbf{1 H}$ remained unchanged (Figure 1f,j,n). This indicates that the binding strength of a protein can be increased by increasing the number of binding motifs (multivalency).

Next, the reversibility of protein binding to the surface was tested by washing with imidazole, a monovalent ligand that competes to bind $\mathrm{Ni}^{2+}$ :NTA, and ethylenediaminetetraacetic 

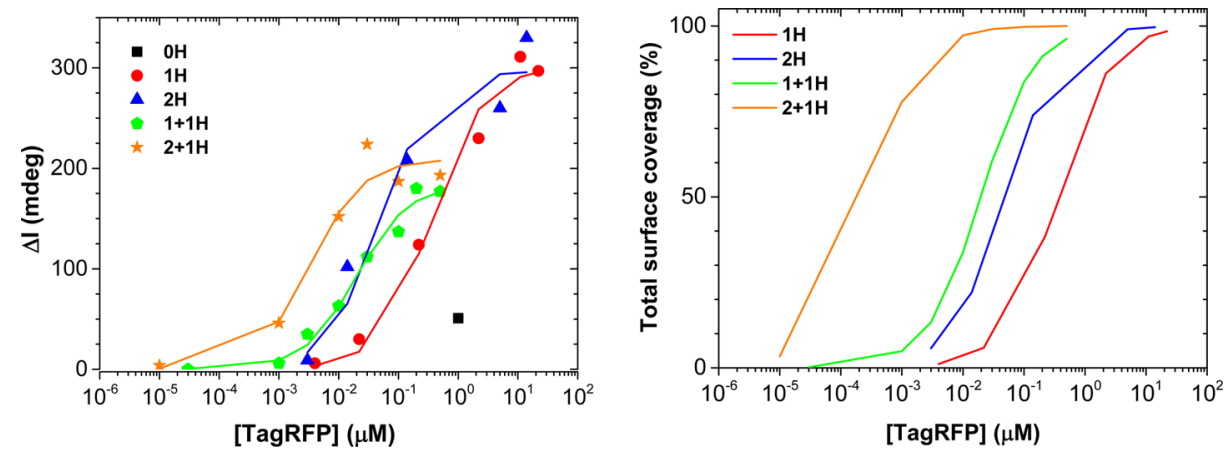

Figure 2. (Left) Maximum response values of SPR titrations of TagRFP variants $0 \mathrm{H}$ (black, squares) $1 \mathrm{H}$ (red, circles), $2 \mathrm{H}$ (blue, triangles), 1 $+1 \mathrm{H}$ (green, pentagons), and $2+1 \mathrm{H}$ (orange, stars) at various concentrations binding to SPR sensors functionalized with $\mathrm{Ni}^{2+}$ :NTA SAMs with their corresponding fits to the multivalency model (see text). (Right) Total surface coverage of the four His ${ }_{6}$-tagged TagRFP variants estimated from fitting each data point to the multivalency model, plotted as lines. Data represent single measurements that have been reproduced.

acid (EDTA) a hexadentated chelating agent for the (effectively irreversible) removal of $\mathrm{Ni}^{2+}$ ions from $\mathrm{Ni}^{2+}$ :NTA (Figure 1). Washing with a large excess of monovalent imidazole resulted in nearly complete reversal of $\mathbf{1 H}$ immobilization (Figure 1c), while $\mathbf{2 H}$ and $\mathbf{1}+\mathbf{1 H}$ showed only reduced intensities (Figure $1 \mathrm{~g}, \mathrm{k}$ ) and $\mathbf{2}+\mathbf{1 H}$ patterns remained essentially unchanged (Figure 1o) when compared with the surfaces after $12 \mathrm{~h}$ of washing in buffer (Figure 1a,e,i,m). These results support the idea that the higher the valency, the higher the resistance to replacement by the competitor, due to increased binding strength of the proteins with the surface. We relate these observations to multivalency, i.e., increased local concentration (see below), and not to cooperativity. While small differences in secondary structure can, in principle, exist between the different His $_{6}$-tags on the protein due to conformation and location on the protein, our molecular dynamics results (see below) show that the conformations of the $\mathrm{His}_{6}$-tags appear to be random coil, as expected, and that the $\mathrm{His}_{6}$-tags point outward, as designed, away from the proteins, as can be seen from the structures in Figure S2, making us believe that multivalent effects are prevailing. The observations from the reversibility experiments are in agreement with literature showing reversible binding of single, short $\mathrm{His}_{6}$-tagged proteins and practically irreversible binding of longer $\mathrm{His}_{10}$-tagged proteins to highvalency $\mathrm{Ni}^{2+}$ :NTA chelating groups on surfaces. ${ }^{55,56,58,59,63}$ By contrast, when washing with EDTA, the $\mathbf{2 H}$ and $\mathbf{1}+\mathbf{1} \mathbf{H}$ patterns were much more severely reduced than when under treatment with imidazole (Figure $1 \mathrm{~h}, \mathrm{l}$ ). As EDTA binds $\mathrm{Ni}^{2+}$, it removes the ion from the complex, preventing any further $\mathrm{His}_{6}-$ tag (re)attachment. Hence, only the highest valency variant $2+$ $1 \mathbf{H}$ can prevent the EDTA-mediated $\mathrm{Ni}^{2+}$ depletion to a significant degree (Figure $1 \mathrm{p}$ ), indicating that $2+\mathbf{1 H}$ is, indeed, the most strongly bound variant.

Surface Binding Affinities. The qualitative findings from fluorescence microscopy were quantified using surface plasmon resonance (SPR). Figure 2 (left) shows maximum SPR responses after reaching thermodynamic equilibrium, for varying concentrations $(10 \mathrm{pM}$ to $20 \mu \mathrm{M})$ of each of the five variants binding to $\mathrm{Ni}^{2+}$ :NTA-functionalized SPR sensors (Scheme S1) as well as their corresponding fits to a multivalency model (Table 1 and described below). Binding was clearly observed for all four $\mathrm{His}_{6}$-tagged proteins, while the control, $\mathbf{0 H}$, shows only minimal binding even at a very high concentration $(1 \mu \mathrm{M})$. These results confirm that the adsorption of TagRFP occurs through specific interaction
Table 1. Optimized Parameters Determined by Fitting the Experimental Data to Langmuir and Multivalency Models ${ }^{a}$

$\begin{array}{lccc}\text { variant } & K_{\mathrm{LM}}\left(\mathrm{M}^{-1}\right) & K_{\mathrm{d}, \mathrm{LM}}(\mathrm{nM}) & C_{\text {eff }}(\mu \mathrm{M}) \\ \mathbf{1 H} & 2.7 \times 10^{6} & 370 & \mathrm{~N} / \mathrm{A} \\ \mathbf{2} \mathbf{H} & 3.8 \times 10^{7} & 26 & 1.8 \\ \mathbf{1}+\mathbf{1 H} & 4.7 \times 10^{7} & 21 & 5.7 \\ \mathbf{2}+\mathbf{1 H} & 2.7 \times 10^{8} & 3.7 & 12\end{array}$

${ }^{a} K_{\mathrm{LM}}$ is the apparent overall binding association constant $\left(K_{\mathrm{d}, \mathrm{LM}}\right.$ is the related binding dissociation constant) obtained from the fit using a 1:1 Langmuir-type model for each variant. $C_{\text {eff }}$ is the effective concentration obtained from a fit using a multivalency model (see text and Methods).

between $\mathrm{His}_{6}$-tags and surface-bound $\mathrm{Ni}^{2+}$ :NTA. Moreover, SPR corroborates the microscopy data, as the binding strength clearly increases, signified by the shifts of the inflection points of the curves of about 1 order of magnitude for each additional His $_{6}$-tag (Figure 2, Table 1). In addition, SPR reveals information about the absolute amount of immobilized protein. The variants with $\mathrm{His}_{6}$-tag(s) on only one side of the $\beta$-barrel ( $\mathbf{1 H}$ and $\mathbf{2 H}$ ) have a maximum attained coverage of approximately $3 \mathrm{ng} / \mathrm{mm}^{2}$, as estimated from the differential SPR angle shift $\left(\Delta \alpha_{\max }\right)$ of around 300 millidegrees (see fitting below). By contrast, the remaining two variants $(1+\mathbf{1 H}$ and 2 $+\mathbf{1 H}$ with $\mathrm{His}_{6}$-tags on opposite sides of the $\beta$-barrel) have a significantly lower maximum attained coverage of around 200 millidegrees. This difference in maximum attainable coverage, as well as the range of concentrations in which a particular mutant reaches a total surface coverage (Figure 2, right), suggests a difference in packing of the proteins on the surface. Each $\mathrm{His}_{6}$-tag contributes to the binding of the proteins to the surface (Table 1 ), which makes it plausible that protein variants with $\mathrm{His}_{6}$-tags on both sides of the $\beta$-barrel absorb in flat, sideon orientations on the surface (see Chart 1 ).

The observed difference in maximum coverage for the variants with binding motifs on only one side of the $\beta$-barrel suggests that those variants prefer to adopt a more upright, endon orientation. This alternative orientation reduces their footprint to provide closer packing, which in turn allows higher surface coverages.

The SPR data were first fitted using a 1:1 Langmuir-type model, ${ }^{27}$ which assumes that each $\mathrm{His}_{6}$-tag interacts as a single entity with the $\mathrm{Ni}^{2+}$ :NTA surface (Table 1 ). The resulting fits are in very good agreement with the experimental SPR data. As 
the Langmuir model yields only overall observable binding constants ( $K_{\mathrm{LM}} ;$ Table 1$)$, we employed a second more detailed model, based on the concept of multivalency and effective concentration $\left(C_{\text {eff }}\right){ }^{67}$ This model provides deeper insight into the differences in binding conformations as a function of the number and position of the $\mathrm{His}_{6}$-tags of the different variants (Methods). Briefly, $C_{\text {eff }}$ is a measure for the (much increased) probability, compared to a monovalent ligand, of a second (or third, etc.) binding moiety of a multivalent ligand attaching to the surface after the first moiety has bound. It takes the form of a concentration (number of molecules per unit volume), as it can be viewed as the number of binding sites the second (or third, etc.) binding moiety could reach within its probing volume (considering steric aspects). For fitting the SPR titration data for $\mathbf{1 H}$, we used the maximum attained coverage $\Delta a_{\max }$ and the intrinsic binding association constant of a single $\mathrm{His}_{6}$-tag $\left(K_{\mathrm{i}, \mathrm{His} 6}\right)$ as variables. We have treated the binding of an entire $\mathrm{His}_{6}$-tag as a single binding event throughout this analysis. We obtain a value for $K_{\mathrm{i}, \mathrm{His} 6}=2.8 \times 10^{6} \mathrm{M}^{-1}\left(K_{\mathrm{d}}=\right.$ $0.36 \mu \mathrm{M}$ ), which is in very good agreement with the $K_{\mathrm{LM}}$ value measured for $\mathbf{1 H}$ (Table 1), indicating that the histidine binding is equal to the overall binding constant. Our value is in agreement with literature values measured in solution for cases where two coordination bonds are formed between $\mathrm{His}_{6}$-tags and trivalent chelating NTAs ${ }^{55}$ and higher than literature values for cases of $\mathrm{His}_{6}$-tag binding to assembled $\mathrm{Ni}^{2+}$ :NTA ligands on $\beta$-CD surfaces, ${ }^{57,63}$ indicating that, here, less than three coordination pairs (see Chart 1) between the $\mathrm{His}_{6}$-tag and surface are formed. Furthermore, the Langmuir fits show that variant $2+\mathbf{1 H}$ binds 1 order of magnitude stronger than the bivalent constructs $\mathbf{2 H}$ and $\mathbf{1}+\mathbf{1 H}$ (Table 1$)$, which is 1 order of magnitude stronger than literature values measured in solution for forming three coordination bonds with trivalent NTA chelating entities, ${ }^{56}$ indicating that more than three coordinating bonds were formed on our surfaces for $\mathbf{2}+\mathbf{1 H}$. For fitting the data of the other variants, $K_{\mathrm{i}, \mathrm{His} 6}$ was fixed to the value found for $1 \mathbf{H}$, while $\Delta a_{\max }$ and $C_{\text {eff }}$ were optimized. The resulting $C_{\text {eff }}$ values of $1.8 \mu \mathrm{M}(\mathbf{2 H}), 5.7 \mu \mathrm{M}(\mathbf{1}+\mathbf{1 H})$, and 12 $\mu \mathrm{M}(\mathbf{2}+\mathbf{1 H})($ Table 1$)$ increase stepwise in magnitude and provide some insight into how the different TagRFP variants attach to the surface. It is worth mentioning at this point that typical $C_{\text {eff }}$ values tend to be in the millimolar range, ${ }^{55,63,68}$ while here they are in the micromolar range. We attribute this fact to our use of $N$-hydroxy succinimide chemistry for the functionalization of the SPR sensors (Scheme S1), which resulted in low surface density of metal-chelating NTA units, which we, in turn, corroborated using X-ray photoelectron spectra (XPS) (Table S3). We did not include an explicit quenching of residual succinimidyl esters in our functionalization protocol because during intensive washing steps these esters are subject to hydrolysis. ${ }^{47}$ A low surface density of NTA puts a much lower number of binding sites in reach of the ligands and, thus, much lower $C_{\text {eff }}$ than obtained previously with, for example, cyclodextrin-terminated SAMs. ${ }^{55,63,68} \mathrm{We}$ emphasize that there is a significant difference between the $\mathrm{His}_{6}$-tag proteins interacting with NTA bound to a surface and with free NTA in solution. In solution NTA moieties are isolated from each other, while on a surface they are immobilized in close proximity to each other, allowing multivalent binding, here responsible for the observed enhanced binding of the multivalently tagged proteins. It is important to realize that any binding experiment in solution between monovalent NTA moieties and any $\mathrm{His}_{6}$-tag of the constructs will lead only to a determination of the monovalent binding event between one NTA moiety and (two) histidine residues. Therefore, we compared our binding constants on our surfaces with referenced solution data of Tampé, Piehler, and co-workers ${ }^{5,57}$ in which the interaction between a trivalent NTA moiety (i.e., three connected NTAs) with His-tags in solution was studied and also represents a case of multivalency where in solution multivalent interactions can occur between the three individual NTA moieties and the histidine residues.

As mentioned above, $C_{\text {eff }}$ is directly proportional to the number of accessible binding sites, which in turn is directly proportional to the (accessible) surface area, with a square dependence on the linker length, $r$, linking the binding moieties. Furthermore, $C_{\text {eff }}$ is inversely dependent on the probing volume, which has a cubic dependence on the linker length, i.e., $C_{\text {eff }} \sim$ area/volume $\sim r^{2} / r^{3}$. With this in mind, it can be reasoned why $2+1 \mathrm{H}$ has the highest $C_{\text {eff }}$ value of $12 \mu \mathrm{M}$. The conformational freedom of the third $\mathrm{His}_{6}$-tag is highly constrained in the divalently bound protein, and this reduction in flexibility reduces the accessible surface area, but more strongly the probing volume, resulting in the high $C_{\text {eff }}$ for the trivalent complex. Interestingly, the $C_{\text {eff }}$ values found for $2 \mathbf{H}$ and $1+1 \mathrm{H}$ clearly differ. $C_{\text {eff }}$ is higher for $1+1 \mathbf{H}$, the variant with the $\mathrm{His}_{6}$-tags on opposite sides of the $\beta$-barrel, than for $\mathbf{2 H}$. This effect can be due only to the difference in position of the second $\mathrm{His}_{6}$-tag, which raises the possibility that site-specific attachment of binding motifs can provide different binding strengths even for complexes with the same number of binding motifs, evident from the separation between $2 \mathbf{H}$ and $\mathbf{1}+\mathbf{1 H}$ data sets in the SPR titration plots in Figure 2. Intuitively, we expected that the necessary side-on orientational change needed to bind the second tag of $\mathbf{1}+\mathbf{1 H}$ is more difficult than the search for a second NTA by the second tag of $2 \mathbf{H}$. However, in the case of end-on binding of $2 \mathbf{H}$, the two $\mathrm{His}_{6}$ tags compete for the same and limited NTA moieties, whereas this does not occur in the case of side-on binding of $1+1 \mathbf{H}$. Moreover, in the case of side-on binding of $\mathbf{1}+\mathbf{1 H}$ additional (possibly competing or repulsive) electrostatic interactions between a larger fraction of the $\beta$-barrel structure and charged NTA moieties could be possible. Taken together, the differences in $K_{\mathrm{LM}}$ and $C_{\text {eff }}$ for the different variants from SPR data, corroborated by our multivalency model, suggest that the binding affinity and orientation of the protein variants on the surface depend on both the position and number of binding motifs present.

Polarization-Resolved Lifetime Imaging on Immobilized Proteins. Polarization-resolved fluorescence lifetime imaging microscopy was performed to compare the anisotropy decay times of end-on and side-on oriented immobilized TagRFP. As concluded from SPR studies, two different types of surface coverages, i.e., packing, for each of which one representative variant was selected. As representative variants for this study, we used the proteins with the highest binding strengths (i.e., stability) per orientation, $\mathbf{2 H}$ (end-on) and $\mathbf{2}+$ $\mathbf{1 H}$ (side-on), as these samples would be most stable in terms of protein adsorption, as the measurements are very timeconsuming (4 to 6 replicas). Representative plots of polarization anisotropy versus time can be found in Figure S15. The proteins were immobilized at the saturation levels determined from SPR (Figure 2). Anisotropy decay times were determined for $2 \mathrm{H}$ and $2+\mathbf{1 H}$ immobilized on various $\mathrm{Ni}^{2+}$ :NTA/PEG line patterns on glass, measuring at different locations on different samples (see Methods for a detailed description of 
sample preparation, setup, and analysis). A plot with all fitted anisotropy lifetimes versus peak intensity is shown in Figure 3.

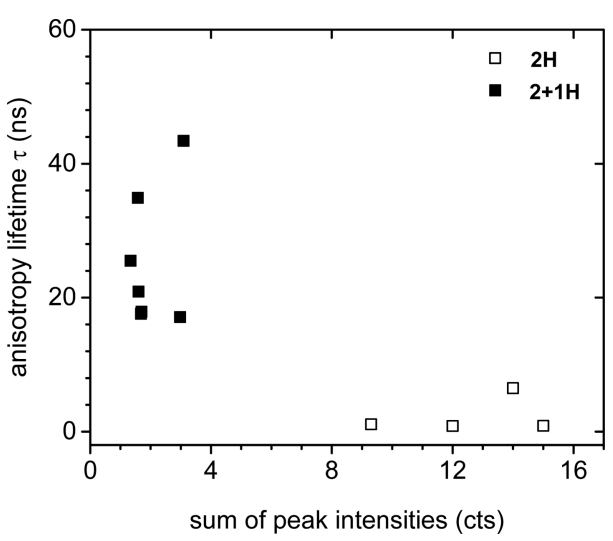

Figure 3. Plot of the fitted anisotropy lifetimes $\tau$ versus the sum of their peak intensities for immobilized $2 \mathrm{H}$ (open squares) and $2+$ 1H (solid squares). Data represent single measurements.

Decay times cluster into two distinct groups (Figure 3) with decay times of $\mathbf{2 H}$ systematically shorter than those of $\mathbf{2}+\mathbf{1 H}$. The X-ray structure of TagRFP shows that the chromophore is oriented approximately perpendicular to the long axis of the barrel. ${ }^{69}$ The distribution of orientations of the chromophores is therefore expected to be the same for end-on and side-on orientation of the proteins on the surfaces, i.e., in both cases randomly oriented transition dipole moments parallel to the surface. The direction of detection is perpendicular to the surface. This means that there will be no difference in orientation dependence of the fluorescence of isolated chromophores (proteins) when comparing end-on and sideon adsorption. Differences in fluorescence intensity should therefore solely stem from differences in the density of proteins on the surface. From this it also follows that there should not be a difference in orientation dependence of polarization anisotropy decay between end-on and side-on orientations. Polarization anisotropy decay is strongly dependent only on the relative distance and orientation of two TagRFP chromophores that undergo energy transfer. Therefore, we believe that the loss of anisotropy could be caused by two conceivable mechanisms: energy transfer between the chromophores of neighboring molecules (homo-FRET) and freedom of movement or rotation. The loss of anisotropy is much faster for $2 \mathbf{H}$, indicating that in this case proteins are either more closely packed, making for more efficient energy transfer between chromophores, or more mobile. When considering that relatively high, saturated, surface coverages were used for these measurements, homo-FRET seems the more likely explanation. The time-resolved anisotropy results, then, support the assumption of more close packing between end-on $(\mathbf{2 H})$ oriented TagRFP variants $(\mathbf{2}+\mathbf{1 H}$ can adsorb side-on; Chart $1)$. We note also that $\mathbf{2 H}$ samples all exhibited much higher fluorescence intensities than $\mathbf{2}+\mathbf{1 H}$ samples (Table S2), which points to a higher surface coverage of $2 \mathbf{H}$ and thus a closer packing for end-on oriented $\mathbf{2 H}$.

Polarization modulation infrared reflection absorption spectroscopy (PM-IRRAS) was carried out on end-on (1H) and end-on $(2+\mathbf{1 H})$ oriented TagRFP immobilized on $\mathrm{Ni}^{2+}$ :NTAfunctionalized gold substrates at saturation levels (Figure 4). The immobilization of protein caused a marked increase in the proportion of the dichroic ratio coming from amide versus

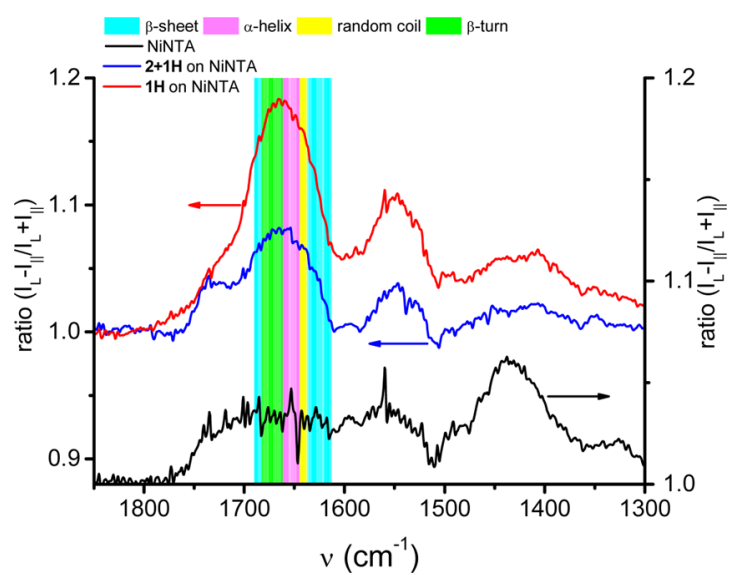

Figure 4. PM-IRRAS differential reflectance spectra of $1 \mathrm{H}$ (red line) and $2+1 \mathrm{H}$ (blue line) immobilized on $\mathrm{Ni}^{2+}$ :NTA SAMs (the black line is the $\mathrm{Ni}^{2+}$ :NTA surface prior to protein binding). Colored bands correspond to regions associated with specific secondary structural elements within the amide I region of the protein, and the changes in these bands are used to elucidate protein orientation. Intensities on the $y$-axis are given as dichroic ratios.

carbonyl groups when compared to bare $\mathrm{Ni}^{2+}$ :NTA layers on gold, as monitored for the amide I band at $1660 \mathrm{~cm}^{-1}$ and the carbonyl stretch vibration of $\mathrm{COOH}$ groups at $1740 \mathrm{~cm}^{-1}$. The amide I to $\mathrm{COOH}$ ratio of unity on bare $\mathrm{Ni}^{2+}$ : NTA rises to 4.5 for $\mathbf{1 H}$ but only to 2.3 for $\mathbf{2}+\mathbf{1 H}$, which is consistent with the existence of more closely packed protein in the case of the endon binding mode.

Furthermore, the amide I band between 1600 and $1700 \mathrm{~cm}^{-1}$ can be largely assigned to $\mathrm{C}=\mathrm{O}$ stretch vibrations, and different regions of this band are correlated with different secondary structural elements of proteins. ${ }^{70}$ More specifically, the signal at $1654 \mathrm{~cm}^{-1}$ corresponds to $\alpha$-helices (magenta) and the dichroic ratio at $1633 \mathrm{~cm}^{-1}$ to $\beta$-sheets (cyan). ${ }^{71}$ Ratios between the dichroic ratios for $\alpha$-helix and $\beta$-sheet were determined to be 1.3 and 1.1 for $1 \mathbf{H}$ and $2+1 \mathbf{H}$, respectively. Since $\mathbf{1 H}$ and $\mathbf{2}+\mathbf{1 H}$ are structurally identical, apart from their number of $\mathrm{His}_{6}$-tags, this observation indicates a difference in orientation. From crystallographic data it can be seen that the only substantial $\alpha$-helical structural element of TagRFP is oriented along the axis of the $\beta$-barrel. Therefore, the $\alpha$-helical $\mathrm{C}=\mathrm{O}$ stretch vibration, which is nearly parallel to the axis of the $\alpha$-helix, should be observable in PM-IRRAS (for high angles of incidence of the polarized light on a conductive surface) only if the protein is oriented end-on. The differential reflectance spectrum of $1 \mathbf{H}$, with its higher relative $\alpha$-helix signal, indicates that the $\beta$-barrel and, thus, the $\alpha$-helix are oriented more endon, or normal to the surface, while the spectrum of $2+1 \mathbf{H}$ indicates that the $\beta$-barrel is oriented more side-on, or parallel to the surface. Taken collectively, all experimental data indicate a distinct preference for an end-on orientation for immobilized TagRFP variants with $\mathrm{His}_{6}$-tags placed on the same side of the $\beta$-barrel, in contrast with side-on orientation taken by alternative TagRFP variants with $\mathrm{His}_{6}$-tags placed on either end of the $\beta$-barrel.

Simulations of $\mathrm{His}_{6}$-Tagged Protein Complexation to $\mathrm{Ni}^{2+}$ :NTA SAMs. In an effort to reveal the atomic-scale details of the effect that the number and positioning of $\mathrm{His}_{6}$-tags has on the strength of the binding interactions as well as the orientation of the protein upon binding to $\mathrm{Ni}^{2+}$ :NTA SAMs, 
molecular dynamics (MD) simulations were performed (see Methods for a detailed description). There have been only a few reports of MD studies on the $\mathrm{Ni}^{2+}$ :NTA-His ${ }_{6}$ system. ${ }^{72-74}$ Most notably, Zhang et al. performed molecular dynamics simulations on a $\mathrm{His}_{6}$-tag interacting with a single $\mathrm{Ni}^{2+}$ :NTA complex and found that the residue pair $\operatorname{His}(2,3)$ was the most stable pair, while secondary structure analysis showed that the $\mathrm{His}_{6}$ structure has a high propensity for random coil conformations. ${ }^{74}$ While MD has been used to describe the behavior of fluorescent proteins in solution ${ }^{75-77}$ as well as the interactions of a green fluorescent protein with a silicon substrate, ${ }^{78}$ there have been, to the best of our knowledge, no MD studies on the immobilization of fluorescent proteins onto SAMs. Therefore, to better understand the atomic-scale structure of the protein-SAM interface, we modeled the immobilization of all our TagRFP proteins with a varying number of $\mathrm{His}_{6}$-tags (Figure S2) to $\mathrm{Ni}^{2+}$ :NTA-modified SAMs. Top and side views of uniform $\mathrm{Ni}^{2+}$ :NTA (control simulation) and mixed $\mathrm{Ni}^{2+}$ :NTA/carboxylic acid SAMs are given in Figures S3 and S4. More ordered SAM structures were formed for the mixed monolayer, ${ }^{79}$ which represents our fabricated low NTA density SAMs. To study the protein-SAM interactions, the histidine residues of the TagRFP variants were placed near $\mathrm{Ni}^{2+}$ :NTA in the SAM in positions where a complex might form. After equilibration, $20 \mathrm{~ns}$ of free dynamics was performed for each complex and showed that the magnitude of the computed protein-SAM interaction energy is directly correlated with the number of histidine residues complexed (Figures S5-S7). The final computed structures of the $\mathrm{His}_{6}$-tags binding to the uniform and mixed $\mathrm{Ni}^{2+}$ :NTA SAMs are given in Figures S8-S13. In general, the $\mathrm{N}$-terminal $\mathrm{His}_{6}$-tag has the largest number of NTA-complexed histidine residues, whereas the Cterminal $\mathrm{His}_{6}$-tag may have fewer complexed histidine residues because of repulsive interactions between the $\mathrm{C}$-terminal region of the TagRFP and the NTA carboxylate oxygens. We estimated a tag-surface interaction energy (summed over electrostatic and van der Waals interactions) of $-190 \mathrm{kcal} / \mathrm{mol}$ (Table S4) for the $\mathrm{His}_{6}$-tag with all six histidine residues bound. This gives an interaction energy per histidine of approximately $-32 \mathrm{kcal} / \mathrm{mol}$, which is similar to the value $(-30 \mathrm{kcal} / \mathrm{mol})$ calculated by Yang et al. ${ }^{80}$ using quantum mechanical simulations of the binding of a $\mathrm{Ni}^{2+}$ ion to one histidine. Computed interaction energies for the uniform and mixed SAMs with all TagRFP variants and orientations are given in Table S4. During simulations on both the uniform and mixed SAMs, the protein remains bound and maintains a nearconstant, to within a few angstroms, center-of-mass height above the surface. Apart from the interactions at the $\mathrm{His}_{6-}$ $\mathrm{Ni}^{2+}$ :NTA binding sites, interactions between the SAM and the proteins are driven mostly by electrostatic interactions involving amino acids with charged side chains on the exterior of the protein and the charged terminal headgroups of the SAM. Also, the protein-SAM interaction energies are much larger for the uniform control SAM (Table S4) since the protein is in direct contact with more of the SAM. For the experimentally used mixed SAM, the interaction energy between the protein and the SAM is comparable to that of the interaction energy between the $\mathrm{His}_{6}$-tag and the SAM (Table S4). To investigate whether on balance the protein prefers a side-on or end-on orientation, the total interaction energy, including protein-water interactions as well as protein-SAM interactions, was evaluated. Increasing the number of $\mathrm{His}_{6}$-tags on the protein gives an increase in the total interaction energy, which agrees with experimental results. However, for both uniform and mixed SAMs, there are no large differences in the interaction energies for proteins immobilized in an end-on compared to a side-on orientation (Table S4). In fact, for both SAMs, the end-on oriented $\mathbf{1 H}$ has less favorable time-averaged interaction energies than $\mathbf{1 H}$ oriented side-on on the SAM. This indicates that the computed loss in proteinSAM interactions on standing up is greater than the gain in protein-water interactions. For $\mathbf{2} \mathbf{H}$ the time-averaged preference for the side-on orientation is smaller than in the case of $\mathbf{1 H}$, but we still do not see a computed preference for the endon orientation, at odds with the experimental observations. From these equilibrium simulations no strong preference in protein orientation can be deduced. We hypothesize that at experimental time scales proteins adopt an end-on orientation simply because it allows more proteins to be immobilized so the magnitude of the protein-SAM interaction energy per unit area is increased, as is the density of lateral protein-protein contacts. We tentatively propose an assembly mechanism analogous to the concentration-dependent assembly of alkanethiol SAMs on gold, ${ }^{81}$ which grow from sparse populations of horizontally oriented single or few-molecule clusters to tightly packed clusters of vertically oriented molecules with intermolecular forces becoming stronger than molecule-surface forces. The protein-surface contact area is approximately doubled when the protein is immobilized sideon, and so larger surface coverages are achieved for the end-on orientation, while the surrounding water density is comparable (Table S5). The protein conformational energy and radius of gyration values show little deviation between bulk solvated and SAM-bound (via the $\mathrm{His}_{6}$-tags) states (Table S6, less than 5\% change in conformational stability and size). This indicates that the $\mathrm{His}_{6}$-tag method of immobilizing proteins allows the protein to be tethered to the SAM surface in its native conformation. This fits with the unchanged fluorescence properties of the proteins upon immobilization, which is known to be a sensitive probe of structural integrity for fluorescent proteins.

We used the computed MD protein-SAM structures as starting points for nonequilibrium steered MD (SMD) simulations to estimate the potential of mean force (PMF) required to remove an immobilized $2 \mathbf{H} \mathrm{His}_{6}$-tagged TagRFP protein from the mixed $\mathrm{Ni}^{2+}$ :NTA SAMs. The SMD simulation was used to pull the protein a distance of $11 \mathrm{~nm}$ away from the SAM over a time of 7 ns. Fifty-eight equally spaced configurations were extracted from the pulling trajectory, and umbrella sampling was performed for $10 \mathrm{~ns}$ on these to obtain the PMF. Figure 5 shows the PMF profiles that were calculated for detachment of $\mathbf{2 H}$ when immobilized in end-on and side-on orientations, while Figures 6 and 7 show key configurations along the unbinding pathways (starting configurations are shown in Figure S14). The two different binding orientations show different desorption paths. It costs approximately $18 \mathrm{kcal} /$ mol to unbind $\mathbf{2 H}$ starting from the end-on orientation, in which only the $\mathrm{His}_{6}$-tags are in contact with the SAM, roughly half the energy required to unbind $\mathbf{2 H}$ starting from the side-on orientation (approximately $38 \mathrm{kcal} / \mathrm{mol}$ ), in which the protein $\beta$-barrel is also in contact with the SAM.

Figure $6 \mathrm{a}$ and $\mathrm{b}$ show configurations of end-on oriented $\mathbf{2 H}$ just before and after, respectively, desorbing the C-terminal His $_{6}$-tag at around $65 \AA$ on the horizontal axis, which agrees with the observation from the equilibrium $\mathrm{MD}$ simulations that the C-terminal $\mathrm{His}_{6}$-tag usually had a lower number of bound 


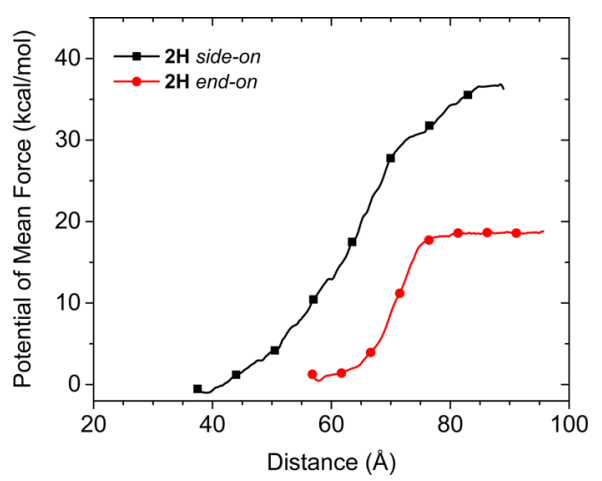

Figure 5. Computed potential of mean force profiles for $2 \mathrm{H}$ desorption in side-on (black squares) and end-on (red circles) orientations. The pulling force is applied to the main body of the protein excluding the $\mathrm{His}_{6}$-tags.

histidine residues, resulting in turn in a lower binding energy (Figure S8). Figure 6c shows the configuration of an intermediate state in which the $\mathrm{N}$-terminal $\mathrm{His}_{6}$-tag was still immobilized and the C-terminal $\mathrm{His}_{6}$-tag was completely detached, and Figure $6 \mathrm{~d}$ shows the configuration after both $\mathrm{His}_{6}$-tags were desorbed. The observation that the core protein barrel of end-on oriented $2 \mathrm{H}$ has practically zero interaction with the SAM (Figure 6) contrasts with the substantial protein-SAM interactions that must be broken to desorb the side-on oriented $2 \mathbf{H}$ (see also computed interaction energies in Table S4). For the side-on oriented $\mathbf{2 H}$, the barrel desorbed from the SAM at a distance of $48 \AA$ (Figure $7 \mathrm{a}$ ) with a $3 \mathrm{kcal} /$ mol magnitude loss in adsorption energy. Then, the C-terminal His $_{6}$-tag desorbed from the SAM at $59 \AA$ (Figure $7 \mathrm{~b}$ ), giving an additional $9 \mathrm{kcal} / \mathrm{mol}$ loss in energy. The N-terminal $\mathrm{His}_{6}$-tag desorbed at $71 \AA$ (configurations shown in Figure $7 \mathrm{c}$ and $\mathrm{d}$ (before and after, respectively)), with an energy difference of 18 $\mathrm{kcal} / \mathrm{mol}$ between the unique events where each of the two $\mathrm{His}_{6}$-tags were desorbing. However, these events were undetectable in the force profile for desorbing side-on oriented $\mathbf{2 H}$ (Figure 7), from which we conclude that it is, nonobviously, the protein pushing against water that contributes the most to the force. Protein adsorbed in the side-on orientation has a higher surface area in the direction of desorption (normal to the plane of the SAM) and also showed a much longer interaction length of $50 \AA$ compared with $20 \AA$ for end-on oriented $\mathbf{2 H}$. Therefore, the PMF data quantify the energy required to disrupt water adlayers as the protein desorbs from the alternative bound conformations, ${ }^{82,83}$ which has been associated with a high entropic cost due to the disruption of the water hydrogen-bonding network.

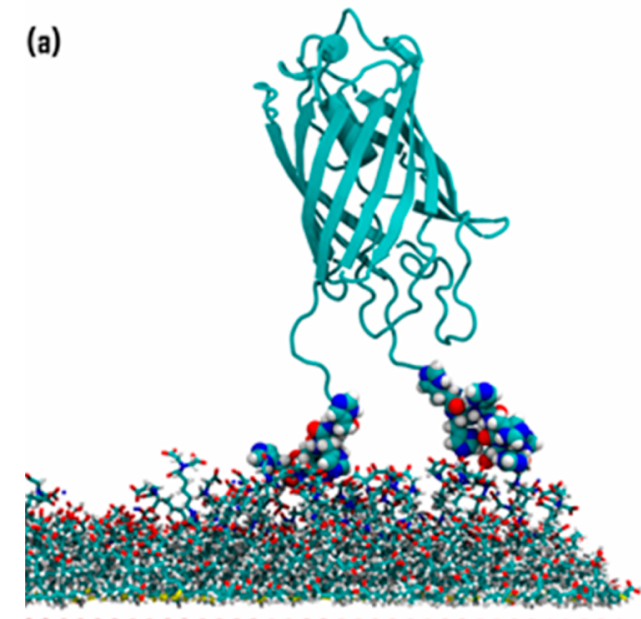

(c)

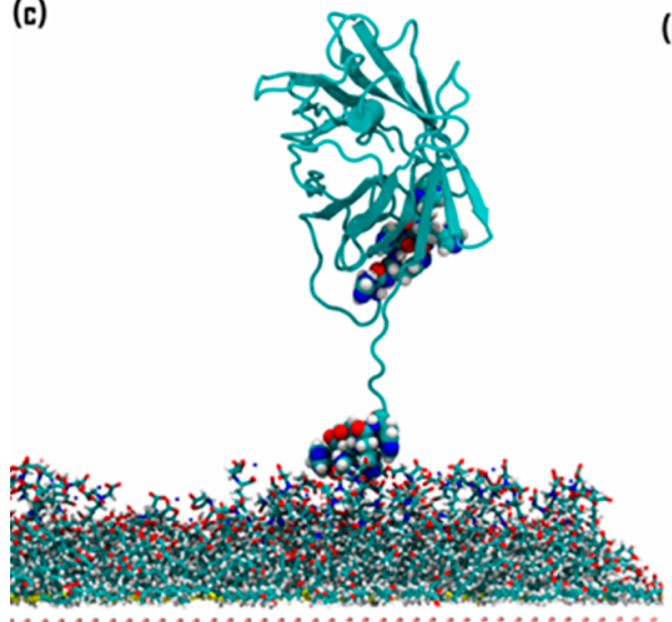

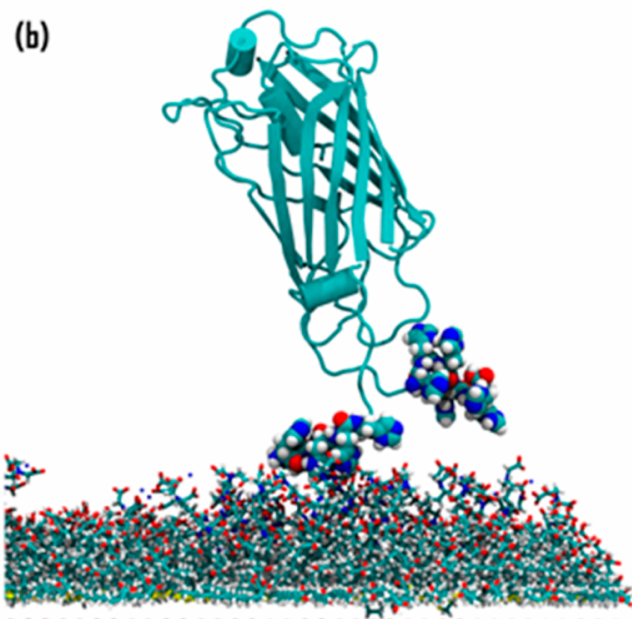

(d)
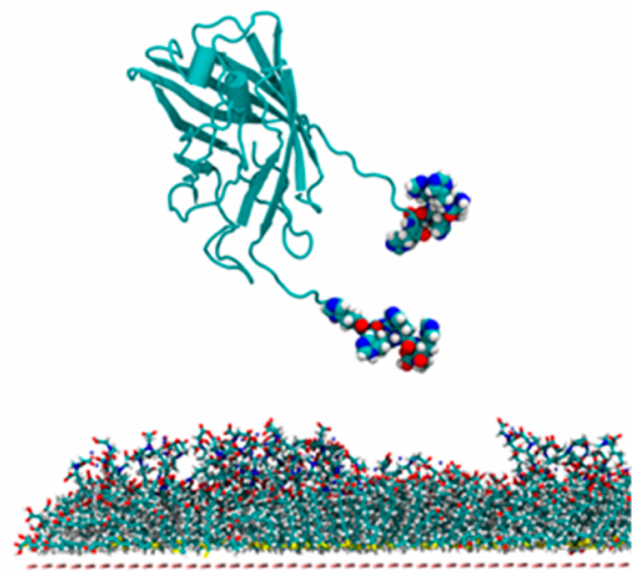

Figure 6. $2 \mathrm{H}$ desorption, starting from an end-on bound orientation. The structures correspond to distances of (a) $64 \AA$; (b) $65 \AA$; (c) $74 \AA$; and (d) $77 \AA$ in the force profile (Figure 5, red curve). 
(a)

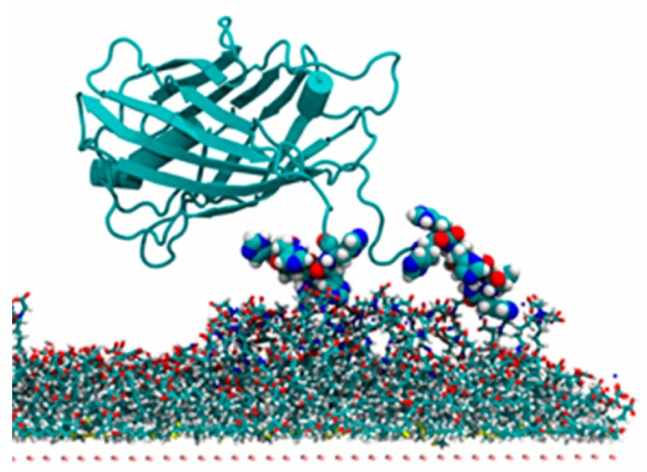

(c)

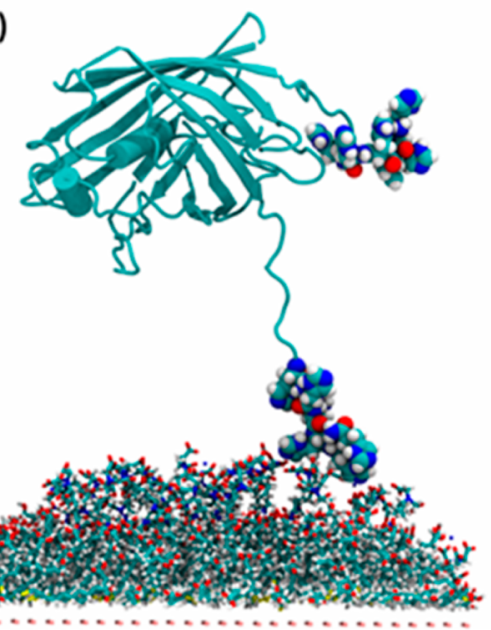

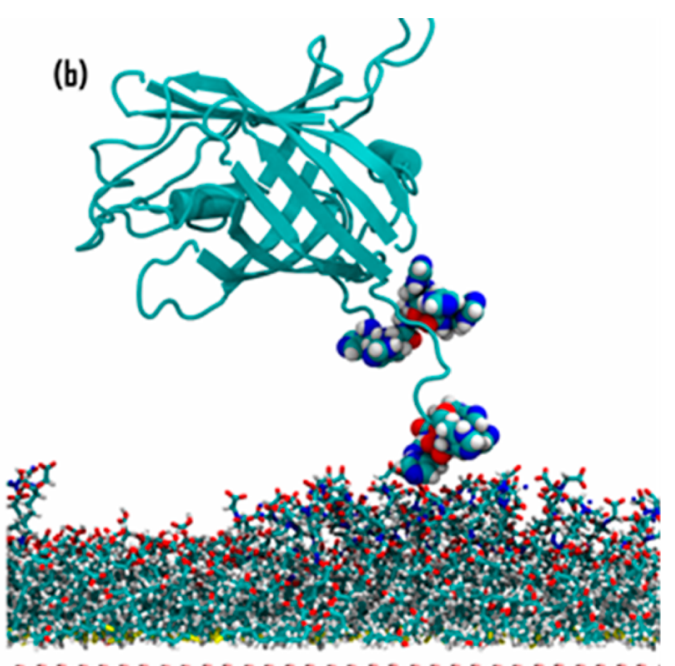

(d)
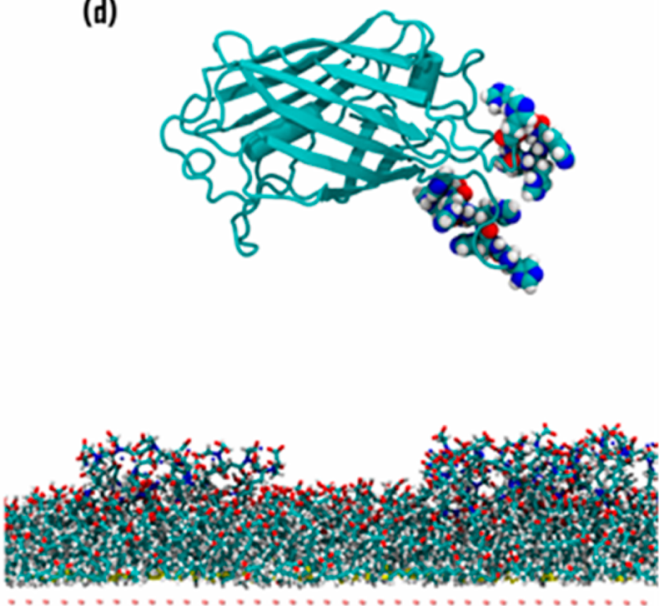

Figure 7. 2H desorption, starting from a side-on bound orientation. The structures correspond to distances of (a) 48 A ; (b) $59 \AA$ A; (c) 70 Å; and (d) $71 \AA$ in the force profile (Figure 5, black curve).

The simulations then complement the experiments by suggesting a binding mechanism in which the protein approaches the surface end-on to minimize disruption to water adlayers (from the PMF calculations) then flips between approximately isoenergetic bound end-on and side-on states (from the equilibrium MD simulations) before (presumably) adopting an end-on orientation to maximize packing with other adsorbing proteins. Future work could involve explicit modeling of the adsorbed protein SAM, which would require sampling of the full range of possible protein-protein and protein-surface orientations, beyond the scope of the present work.

\section{CONCLUSIONS}

Proteins have been successfully engineered with strategically placed $\mathrm{His}_{6}$-tags on both $\mathrm{N}$ - and C-termini and a solventaccessible loop of TagRFP. Steady-state and time-dependent spectroscopic properties of five mutants and conjugates matched those of the wild-type TagRFP. The binding strength of the variants increased with increasing numbers of binding motifs as qualitatively assessed by following fluorescent patterns in reversibility and competition experiments. These findings were corroborated by SPR studies signifying that each additional $\mathrm{His}_{6}$-tag increases the binding strength by 1 order of magnitude. With each $\mathrm{His}_{6}$-tag contributing to the binding of the proteins to the surface, additional information from SPR revealed that the absolute amount of immobilized proteins was reduced by a third when placing the binding motifs on opposite sides of the barrel. With binding motifs placed on the same side of the barrel a more upright, end-on orientation is adopted, while binding motifs placed at opposite sides of the barrel give a preference for a flat, side-on orientation. Measured binding affinities and binding modes calculated in the molecular simulations have shown that not all histidine residue pairs are involved in complexation, due to a combination of repulsive interactions between the protein and the solvated surface interactions and sterical hindrance at the $\mathrm{His}_{6}-\left(\mathrm{Ni}^{2+}-\mathrm{NTA}\right)_{3}$ sites. Time-resolved fluorescence anisotropy techniques verified that the orientation and thus coverage cause distinct, different fluorescent lifetime characteristics. Potential of mean force calculations coupled with calculated protein-surface adsorption energies suggest that the experimentally measured end-on orientation is a supra-protein effect driven by maximization of horizontal protein-protein interactions as the "footprint" of each individual protein is reduced.

The scientific challenge of this work was to provide evidence that protein immobilization occurs with envisioned control over orientation, surface coverages, affinities, and function. Firm structural evidence of uniformly oriented proteins is currently lacking, and firm quantification of binding characteristics by 
experiment and theory is lacking in most if not all protein immobilization studies. With this contribution we show evidence and discussion that tunable control over the orientation and binding strength of protein immobilization can be achieved by well-considered placement of multivalent binding motif(s) on the protein. We realize that in light of further development and understanding of protein immobilization and tag placement on the proteins it would be interesting to optimize the $\mathrm{His}_{6}$-tag NTA interaction by finding ways to fully involve each and every residue of all $\mathrm{His}_{6}$-tags in the formation of the maximum number of six coordination bonds with surface-bound NTA. We show by experiment and theory that this is not the case and that the solution to this challenge should not be sought in whether $\mathrm{N}$ - and C-termini or loops are chosen for tagging but rather in the spacing of the entire hexahistidine tag with respect to the protein and, equally important, the internal spacing of two histidine residues with respect to two other histidines to avoid steric crowding effects between the six histidine residues with the surface-bound NTA moieties.

The strict correlation between the intact tertiary structure (i.e., folding) and the unchanged fluorescence characteristics of fluorescent proteins makes them excellent model systems to probe the preservation of structural integrity of the protein upon immobilization. Any impairment of the structural integrity of the fluorescent protein would immediately lead to drastic changes in fluorescence characteristics, such as its intensity and lifetime, which can be observed by state-of-the-art fluorescence microscopy. A comparison of the relevant time traces showed no significant changes in fluorescence lifetimes between samples with proteins adsorbed side-on and end-on; only the anisotropy decay changed significantly. The realization of design of orientation of immobilized proteins not only is important for the fluorescent protein field itself but would be applicable to a range of much broader fields, such as the fundamental study of the protein dynamics and chemistry (folding, maturation, etc.) while being attached to an immobile surface. These developments are also highly relevant to fields to improve the performance of proteins when using $\mathrm{His}_{6}$-tag (or other tags) technology in diagnostic assays, purification protocols, and immobilization studies. Broad application of the results is foreseen when employing weak to moderate supramolecular interactions to immobilize proteins in applications where (reversible) control over orientation, binding strength, surface coverage, and function is required to optimize the performance of the assay, material, or device.

\section{METHODS}

Materials. Maleimide caproic acid hexa(histidine) $\left(\right.$ mic-His $\left._{6}\right)$ was purchased from JPT Peptide Technologies, Germany. All solvents were of p.a. quality and purchased from Biosolve (Valkenswaard, The Netherlands). All other starting compounds were purchased from Acros (Geel, Belgium) or Sigma-Aldrich (Zwijndrecht, The Netherlands). All compounds were used as received unless stated otherwise. Deuterated solvents used for NMR spectroscopy were purchased from Cambridge Isotope Laboratories, and the water used was always of Milli-Q quality (Millipore, $R=18.2 \mathrm{M} \Omega \cdot \mathrm{cm}$ ).

Preparation of ${ }^{\mathrm{N} \mathrm{His}_{6}}{ }^{\text {wt }}$ TagRFP. The following primers were used for PCR amplification of ${ }^{\text {wt } T a g R F P ~ u s i n g ~ p T a g R F P-C ~(E v r o g e n ~ J S C) ~}$ as DNA template: 5'-cgcggatccaatgagcgagctgattaaggagaacatgca- $3^{\prime}$ containing a unique $B a m \mathrm{H}^{\mathrm{I}}$ restriction site (underlined) and $5^{\prime}$ cgcgaattccttgtgccccagtttgctag- $3^{\prime}$ containing a unique EcoR I restriction site (underlined). The PCR product was purified and digested with $B a m \mathrm{H}$ I and EcoR I restriction enzymes (NEB) and ligated into
pRSETB plasmid (Invitrogen), digested with the same restriction enzymes. pRSETB contains an $\mathrm{N}$-terminal hexahistidine tag $\left({ }^{\mathrm{N}} \mathrm{His}_{6}\right.$ tag) for nickel-affinity purification and an enterokinase recognition site (DDDDK) to allow for the subsequent cleavage of the His ${ }_{6}$-tag. The resulting plasmid, pRSETB- ${ }^{\text {wt }}$ TagRFP, was first transformed into E. coli (XL10 gold, Stratagene) using standard procedures in the presence of ampicillin $(100 \mathrm{mg} / \mathrm{L})$ for amplification and further mutagenesis. pRSETB- ${ }^{\mathrm{wt}}$ TagRFP plasmid was also transformed into E. coli BL21 pLysS using standard procedures in the presence of ampicillin (100 $\mathrm{mg} / \mathrm{L})$ and chloramphenicol ( $34 \mathrm{mg} / \mathrm{L})$ for protein expression. Singlecolony transformants were selected, and precultures were grown overnight at $37^{\circ} \mathrm{C}$. These precultures were each used to inoculate $2 \mathrm{~L}$ of LB medium containing ampicillin $(100 \mathrm{mg} / \mathrm{L})$ and chloramphenicol $(34 \mathrm{mg} / \mathrm{L})$ at $37^{\circ} \mathrm{C}$ with shaking until an $\mathrm{OD}_{600}=0.6$ was reached. The cultures were cooled to $16{ }^{\circ} \mathrm{C}$ before protein expression was induced with isopropyl- $\beta$-D-thiogalactopyranoside (IPTG) to a final concentration of $1 \mathrm{mM}$ and incubated overnight at $16^{\circ} \mathrm{C}$. Cells were harvested by centrifugation at $4000 \mathrm{~g}$ at $4{ }^{\circ} \mathrm{C}$ for $20 \mathrm{~min}$. The resulting cell pellets were resuspended for $20 \mathrm{~min}$ in BugBuster reagent with benzonase nuclease (Novagen) according to the supplier's instructions. The lysate was cleared by centrifugation at $16000 \mathrm{~g}$ for $30 \mathrm{~min}$ at $4{ }^{\circ} \mathrm{C}$. $\mathrm{Ni}^{2+}$ :NTA agarose beads (QIAGEN) were added to the proteincontaining supernatant at a $1: 10 \mathrm{v} / \mathrm{v}$ ratio, respectively, and incubated at $4{ }^{\circ} \mathrm{C}$ for at least an hour with slow but continuous mixing. The agarose beads were filtered and washed with wash buffer $(20 \mathrm{mM}$ Tris buffer, $300 \mathrm{mM} \mathrm{NaCl}, 20 \mathrm{mM}$ imidazole, $\mathrm{pH} 8.0$ ), and the bound protein fraction was eluted with elution buffer $(20 \mathrm{mM}$ Tris buffer, 300 $\mathrm{mM} \mathrm{NaCl}, 1 \mathrm{M}$ imidazole, $\mathrm{pH}$ 8.0). The purified ${ }^{\mathrm{N}} \mathrm{His}_{6}{ }^{-{ }^{\mathrm{wt}} \text { TagRFP }}$ fractions $(\sim 30 \mu \mathrm{M})$ were subsequently rebuffered using PD10 columns (GE Healthcare) into $0.1 \times$ PBS $(0.8 \mathrm{mM}$ phosphate buffer, $14.4 \mathrm{mM} \mathrm{NaCl}, 0.27 \mathrm{mM} \mathrm{KCl}, \mathrm{pH} 7.4$ ), aliquoted, snap-frozen in liquid nitrogen, and stored at $-80^{\circ} \mathrm{C}$. The protein was characterized using SDS- and native PAGE (Figure S1), UV-vis, steady-state and time-resolved fluorescence spectroscopy, and MALDI-TOF mass spectrometry (see below).

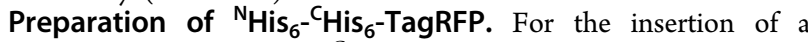
second, $\mathrm{C}$-terminal $\mathrm{His}_{6}$-tag $\left({ }^{\mathrm{C}} \mathrm{His}_{6}\right.$-tag), the following procedure was used regardless of the mutant. The TagRFP gene was amplified using $5^{\prime}$-cgcggatccaatgagcgagctgattaaggagaacatgca-3' (BamH I restriction site is underlined) and $5^{\prime}$-gcggaattcttagtggtggtggtggtggtgcttgtgccccagtttgcta-3' (EcoR I restriction site is underlined, encoding a His ${ }_{6}$-tag) as forward and reverse primers, respectively, and pRSETB-TagRFP as DNA template. After PCR purification, the gene product and pRSETB-TagRFP were digested sequentially, first with EcoR I, then $B a m \mathrm{H} \mathrm{I}$, according to the manufacturer's instructions. DNA ligations were performed using T4-ligase (NEB) at $16{ }^{\circ} \mathrm{C}$ overnight, and the resulting pRSETB-TagRFP-His ${ }_{6}$ plasmid was transformed into E. coli (XL10 gold, Stratagene) competent cells according to standard procedures in the presence of ampicillin $(100 \mathrm{mg} / \mathrm{L})$ for amplification and further mutagenesis. pRSETB- ${ }^{\text {wt }}$ TagRFP-His $_{6}$ plasmid was also transformed into E. coli BL21 pLysS in the presence of ampicillin (100 $\mathrm{mg} / \mathrm{L})$ and chloramphenicol $(34 \mathrm{mg} / \mathrm{L})$. Single-colony transformants were selected, and precultures were grown overnight at $37^{\circ} \mathrm{C}$. These precultures were each used to inoculate $2 \mathrm{~L}$ cultures of $E$. coli BL21 pLysS cells, which were grown at $37^{\circ} \mathrm{C}$ to $\mathrm{OD}_{600}=0.6$ and cooled to $16{ }^{\circ} \mathrm{C}$, and protein expression was induced with IPTG to a final concentration of $1 \mathrm{mM}$. The culture was incubated overnight at $16^{\circ} \mathrm{C}$. The cells were harvested by centrifugation $(4000 \mathrm{~g}, 20 \mathrm{~min}$ ) and lysed using BugBuster (as described above). Protein purification and characterization were carried out as described above.

Preparation of ${ }^{\mathrm{N}} \mathrm{His}_{6}-{ }^{\mathrm{S} 128 \mathrm{C}} \mathrm{TagRFP}, \mathrm{N}^{\mathrm{His}} \mathrm{Hi}_{6}-\mathrm{C}^{-} \mathrm{His}_{6}{ }^{\mathrm{S} 128 \mathrm{C}}$ TagRFP, ${ }^{\mathrm{N}} \mathrm{His}_{6}$-TagRFP (1H), and ${ }^{\mathrm{N}} \mathrm{His}_{6}{ }^{-}{ }^{\mathrm{C}} \mathrm{His}_{6}$-TagRFP (2H). By site-directed mutagenesis (QuikChange Multi kit, Stratagene Technologies), selected mutations were introduced into pRSETB- ${ }^{\text {wt }}$ TagRFP (for both singly- and doubly-His ${ }_{6}$-tagged TagRFP) using the following primers: S128C forward 5 '-ggtgaacttcccatgcaacggccctgtga- $3{ }^{\prime}$; reverse $5^{\prime}$-tcacagggccgttgcatgggaagttcacc-3'; C222S forward $5^{\prime}$-ggctgtggccagatactccgacctccc-3'; reverse $5^{\prime}$-gggaggtcggagtatctggccacagcc- $3^{\prime}$; C114S forward $5^{\prime}$-gcctccaggacggctccctcatctacaac- $3^{\prime}$; reverse $5^{\prime}$ gttgtagatgagggagccgtcctggaggc- $3^{\prime}$. 
Mutations S128C, C222S, and C114S yielded mutants "S128C TagRFP" containing a single accessible cysteine residue in a loop at the top of the $\beta$-barrel. Mutations C222S and C114S yielded mutants "TagRFP" with no accessible cysteine residues left. All mutant variants were expressed and purified under the same conditions as the wild-type, to yield ${ }^{\mathrm{N}} \mathrm{His}_{6}{ }^{-}{ }^{\mathrm{S} 128 \mathrm{C}} \mathrm{TagRFP},{ }^{\mathrm{N}} \mathrm{His}_{6^{-}}{ }^{\mathrm{C}} \mathrm{His}_{6-}{ }^{\mathrm{S}}{ }^{\mathrm{S}}{ }^{28 \mathrm{C}} \mathrm{TagRFP}$, ${ }^{\mathrm{N}} \mathrm{His}_{6}$-TagRFP (1H), and ${ }^{\mathrm{N}} \mathrm{His}_{6}{ }^{-}{ }^{\mathrm{C}} \mathrm{His}_{6}$-TagRFP (2H). Characterization by SDS- and native PAGE (Figure S1), UV-vis, steady-state and time-resolved fluorescence spectroscopy, and MALDI-ToF mass spectrometry (see below) was carried out and confirmed the successful expression and purification of the respective proteins. The mutants showed no discernible differences regarding their photophysical properties from the wild-type variants ${ }^{\mathrm{N}} \mathrm{His}_{6}{ }^{\text {wt }}{ }^{\mathrm{wt}}$ TagRFP and ${ }^{\mathrm{N}} \mathrm{Hi}$ $\mathrm{s}_{6}{ }^{-}{ }^{\mathrm{C}} \mathrm{His}_{6}{ }_{6}{ }^{\mathrm{wt}} \mathrm{TagRFP}$, thus indicating that their overall structure and fluorescence properties upon site-directed mutagenesis are retained.

Preparation of ${ }^{\text {wt }}$ TagRFP without $\mathrm{His}_{6}$-Tags $(\mathrm{OH})$. Removal of the $\mathrm{His}_{6}$-tag from the ${ }^{\mathrm{N}} \mathrm{His}_{6}{ }^{\mathrm{wt}} \mathrm{TagRFP}$ was accomplished by enterokinase digestion using enterokinase (Invitrogen) and its corresponding enterokinase removal kit (EKaway, Invitrogen) according to the manufacturer's instructions. In short, enterokinase digestion of ${ }^{\mathrm{N}} \mathrm{His}_{6}{ }^{-}{ }^{\mathrm{wt}} \mathrm{TagRFP}$ was carried out overnight at $37{ }^{\circ} \mathrm{C}$ using protein stock solution with varying amounts of enzyme, where undigested protein served as negative control. Cleavage was nearly complete using 4 units of enterokinase per $20 \mu \mathrm{g}$ of ${ }^{\mathrm{N}} \mathrm{His}_{6}{ }^{-{ }^{\mathrm{wt}} \mathrm{TagRFP} \text {. }}$ After digestion, enterokinase was removed by letting it bind to the removal kit's enterokinase-binding resin, which was, in turn, removed by centrifugation $(5000 \mathrm{~g}, 2 \mathrm{~min})$. Subsequently, residual, undigested protein was removed using nitrilotriacetatenickel $\left(\mathrm{Ni}^{2+}: \mathrm{NTA}\right)$-affinity chromatography, resulting in a flow-through fraction of pure, $\mathrm{His}_{6}$-tagfree ${ }^{\text {wt }}$ TagRFP $(\mathbf{0 H})$. Characterization by SDS-/native PAGE and Western blotting (Figure S1), UV-vis, and steady-state and timeresolved fluorescence spectroscopy (see below) was carried out and confirmed the successful expression and purification of $\mathbf{0 H}$.

Preparation of ${ }^{\mathrm{N}} \mathrm{His}_{6}{ }^{\mathrm{C}} \mathrm{His}_{6}{ }^{\mathrm{S}}{ }^{288 C} \mathrm{His}_{6}-\mathrm{TagRFP}(2+1 \mathrm{H})$ and ${ }^{\mathrm{N}} \mathrm{His}_{6}{ }^{-}{ }^{-128 C} \mathrm{His}_{6}$-TagRFP $(1+1 \mathrm{H})$ Conjugation. ${ }^{\mathrm{N}} \mathrm{His}_{6}{ }^{-}{ }^{\mathrm{S} 28 \mathrm{C}}$ TagRFP and ${ }^{\mathrm{N}} \mathrm{His}_{6}{ }_{6}{ }^{\mathrm{C}} \mathrm{His}_{6}{ }^{\mathrm{S} 128 \mathrm{C}}$ TagRFP, which both possess a single accessible cysteine residue at position 128 , were conjugated with a thiol-reactive maleimide-functionalized oligopeptide, maleimide caproic acid hexa(histidine) (mic-His ${ }_{6}$ ), to yield ${ }^{\mathrm{N}} \mathrm{His}_{6}{ }^{-}{ }^{1128 \mathrm{C}} \mathrm{His}_{6}$-TagRFP $(\mathbf{1}+\mathbf{1 H})$ and ${ }^{\mathrm{N}} \mathrm{His}_{6}{ }^{\mathrm{C}} \mathrm{His}_{6}{ }^{-}{ }^{\mathrm{S} 28 \mathrm{C}} \mathrm{His}_{6}$-TagRFP $(\mathbf{2}+\mathbf{1 H})$, respectively. As negative and control ${ }^{\mathrm{N}} \mathrm{His}_{6}$-TagRFP and ${ }^{\mathrm{N}} \mathrm{His}_{6}{ }^{-}{ }^{\mathrm{C}} \mathrm{His}_{6}$-TagRFP were used, respectively. Conjugations were carried out by first reducing the cysteine residues using $10 \mathrm{mM}$ phospate buffer $(\mathrm{PB})$ containing 0.1 $\mathrm{mM}$ dithiothreitol (DTT) ( $\mathrm{pH} \mathrm{8.0)}$ for $30 \mathrm{~min}$ and removing the DTT again (Zeba Spin, Thermo Scientific) and then by incubating a 10:1 mixture of maleimide/protein $(\sim 20 \mu \mathrm{M})$ in $10 \mathrm{mM} \mathrm{PB}(\mathrm{pH} 8.0)$ in the dark for $24 \mathrm{~h}$ at room temperature (RT). The reactions were subsequently quenched by adding a 10 -fold molar excess (with respect to the maleimide) of DTT for $30 \mathrm{~min}$ at RT, after which the samples were rebuffered (Zeba Spin, Thermo Scientific) into 0.1× PBS at least three times to remove any residual peptide and DTT. Characterization was performed as described above, and conjugation yields were typically in the range $30-50 \%$ (see below).

Purification of the $\mathrm{His}_{6}$-tagged conjugates was conducted using an Äkta FPLC system and a $1 \mathrm{~mL}$ HisTrap HP column (GE Healthcare) according to the manufacturer's instructions. Conjugates containing two and three $\mathrm{His}_{6}$-tags could be separated from the native proteins containing one and two $\mathrm{His}_{6}$-tags, respectively, and were isolated and characterized using SDS- and native PAGE (Figure S1) as well as MALDI-ToF MS (see below). The overall purity was found to be at least $>80 \%$ after purification and rebuffering into $0.1 \times$ PBS using PD10 spin columns (GE Healthcare).

Surface Plasmon Resonance. SPR measurements were performed using instruments in Kretschmann configuration: either a Resonant Technologies GmbH (Germany) RT2005 SPR setup or an IBIS Technologies imaging SPR (iSPR) system (see below). In both cases glass substrates covered with a $50 \mathrm{~nm}$ gold layer were used. On the gold, $\mathrm{Ni}^{2+}$ :NTA was self-assembled into a monolayer via $\mathrm{Au}-$ sulfide interactions (see below). In the case of the Resonant Technologies setup, these substrates were attached to a $70 \mu \mathrm{L}$ volume microfluidic cell mounted on a prism, which in turn was mounted on a double goniometer head, with which the angle of incidence of the exciting laser on the prism (Schott, LaSFN9) could be controlled. Light from a $2 \mathrm{~mW}$ HeNe laser of $633 \mathrm{~nm}$ wavelength passed through the prism and onto the substrate. The intensity of the reflected light from the substrate was measured by a large-area photodiode. In both setups the gold-on-glass substrate was optically matched to the prism using index matching oil (Cargille; series $\mathrm{B} ; n_{\mathrm{D}}{ }^{25}=1.700 \pm 0.002$ ). Imaging SPR measurements on the iSPR (IBIS Technologies), also set up in Kretschmann configuration, using a laser of $800 \mathrm{~nm}$ wavelength, were performed on the above type of substrates, and various regions of interest were assigned, for each of which SPR sensograms were determined, individually. Here too, the resonance angle was determined by continuously scanning through the surface plasmon resonance dip and finding the minimum, during binding experiments in a flow-cell. PBS with $0.01 \%$ Tween-20 was used as a running buffer in all experiments. All SPR experiments were performed at a continuous flow rate of $20 \mu \mathrm{L} / \mathrm{min}$.

Steady-State and Time-Dependent Spectroscopy. Absorption spectra of all fluorescent proteins, their mutants, and conjugates were recorded using a Perkin Elmer LAMBDA850 UV/vis spectrophotometer. Fluorescence spectra and lifetime data of all fluorescent proteins, their mutants, and conjugates were recorded using a JobinYvon-Horiba Fluoromax4 fluorimeter including a TCSPC system for time-dependent measurements with pulsed LEDs for excitation at $561 \mathrm{~nm}$. Results are summarized in Table S1.

Fluorescence Microscopy. Steady-state fluorescence microscopy images were recorded using an Olympus IX71 inverted microscope equipped with a U-RFL-T mercury burner lamp as light source and a digital Olympus DR70 color camera for image acquisition. Olympus filter cubes with appropriate band-pass or long-pass filters and dichroic mirrors (Semrock) were used. Fluorescence micrographs were acquired using a $20 \times$ Fluorplan objective from Olympus and exposure times of $2 \mathrm{~s}$.

Fluorescence Anisotropy Measurements. Fluorescence anisotropy measurements were carried out on a custom-made microscope based on an Olympus IX71 body. Light from a Fianium SC 400-2-PP super continuum laser was passed through an acousto-optical tunable filter set to $515 \mathrm{~nm}$ and an additional band-pass filter (FF01-520/15, Semrock) into the microscope. The light was passed through a linear polarization filter (LPVISA100, Thorlabs) and focused on the sample with an Olympus UplanSApo 60× 1.2 NA water immersion objective. The generated fluorescence was filtered using a long-pass filter (LLP01-532R, Semrock) and a polarizer (LPVISB, Thorlabs). Detection was performed by an avalanche photodiode (PDM, Micro Photon Devices) that is connected to a Becker \& Hickl SPC-830 counting card operating in time-tagged mode. For each measurement (all at equal exposure times) two sequential images of the same region were taken, one with the polarization parallel to the polarized excitation and one perpendicular; the results were checked to be independent of the order of acquisition. The anisotropy lifetime was obtained using a commercial software package (FluoFit v4.5, PicoQuant) by a fit of the observed time-dependent anisotropy using a single-exponential decay. Intensities were the sum of the peaks of the parallel and perpendicular time traces.

Mass Spectrometry. Mass spectrometry of small molecules and peptides was performed using a Waters micromass LCT ESI mass spectrometer. Mass spectrometry on all protein variants and conjugates was carried out using a MALDI ToF mass spectrometer (Voyager-DE-RP, Applied Biosystems) and sinapinic acid as matrix. Protein samples were desalted prior to spotting on the sample plate, and all measurements were carried out on several spots per sample with varying protein concentrations. For a summary of the mass spectrometry data of protein variants see Table S1.

Infrared Reflection Absorption Spectroscopy Measurements. Infrared spectra were recorded on monolayers of proteins immobilized on glass substrates covered with a thin layer of gold, which in turn was modified with a self-assembled thiol-monolayer terminated with $\mathrm{Ni}^{2+}$ :NTA (see below), using a Thermo Fisher PM- 
IRRAS system under an angle of incidence of $81^{\circ}$. Protein immobilization was carried out according to the protocol below.

X-ray Photoelectron Spectroscopy. XPS were recorded using a Physical Electronics Quantera SXM (scanning XPS microprobe) spectroscope using the $\mathrm{Al} \mathrm{K} \alpha$ line as monochromatic X-ray source at $1486.6 \mathrm{eV}$. For all samples one survey spectrum to identify regions for element analysis and 3 element scans per analyzed element were recorded in order to determine the relative abundance of carbon, sulfur, and, where present, nitrogen (Table S3). Spectra were recorded on 4 samples on 1 in. glass wafers covered with a $50 \mathrm{~nm}$ thick gold layer functionalized with monolayers (see below) of (1) 11mercaptoundecanoic acid (MUA); (2) $N$-hydroxysuccinimide (NHS)-activated MUA; (3) $N_{\alpha}, N_{\alpha}$-bis(carboxymethyl)-L-lysine (NTA-NH - -functionalized MUA; and (4) nickel(II) nitrilotriacetatenickel $\left(\mathrm{Ni}^{2+}: \mathrm{NTA}\right)$-functionalized MUA.

Preparation of $\mathrm{Ni}^{2+}$ :NTA Monolayers on Gold-Coated Substrates. SPR sensors ( 1 in., Ssense) were cleaned in a solution of $\mathrm{H}_{2} \mathrm{SO}_{4} / \mathrm{H}_{2} \mathrm{O}_{2}, 3: 1$ (which should be handled with care, as it reacts violently with organic material), for $30 \mathrm{~s}$, rinsed with water, dried in a flow of $\mathrm{N}_{2}$, and subsequently immersed in a solution of 2 mM MUA in 1:1 EtOH/water and left at least $16 \mathrm{~h}$ under ambient conditions to react. To remove any excess MUA, the samples were rinsed thoroughly with $\mathrm{EtOH}$ and dried in a flow of $\mathrm{N}_{2}$. The resulting carboxylic acid-terminated monolayers were activated using a freshly prepared solution of $300 \mathrm{mM}$ NHS and $40 \mathrm{mM} \mathrm{N}$-(dimethyl aminopropyl)- $\mathrm{N}^{\prime}$-ethylcarbodiimide (EDC) in $40 \mathrm{mM} \mathrm{PB}, \mathrm{pH}$ 8.0, for at least $30 \mathrm{~min}$ under ambient conditions. After the reaction, the samples were rinsed with water and dried in a flow of $\mathrm{N}_{2}$, and the activated ester-terminated monolayers were immediately reacted with a $1 \mathrm{mM}$ solution of $N_{\alpha}, N_{\alpha}$-bis (carboxymethyl)-L-lysine hydrate in 40 $\mathrm{mM} \mathrm{PB}, \mathrm{pH}$ 8.0, for $2 \mathrm{~h}$ under ambient conditions. Samples were then washed with water, incubated for $30 \mathrm{~min}$ in a $5 \mathrm{~g} / \mathrm{L}$ aqueous solution of $\mathrm{NiCl}_{2} \cdot 6 \mathrm{H}_{2} \mathrm{O}$, washed with water, and dried in a flow of $\mathrm{N}_{2}$; the samples could be stored under dry $\mathrm{N}_{2}$ for a maximum of 4 weeks before use.

Preparation of Bifunctional NTA/PEG-Line-Patterned Glass Substrates Using Nanoimprint Lithography. Four-inch Borofloat (Schott, Borofloat 33) glass wafers were immersed in a solution of $\mathrm{H}_{2} \mathrm{SO}_{4} / \mathrm{H}_{2} \mathrm{O}_{2}, 3: 1$ (which should be handled with care, as it reacts violently with organic material), for $10 \mathrm{~min}$, rinsed with water, dried in a flow of $\mathrm{N}_{2}$, and subsequently spin-coated (Speedline, p6700) with a $6 \% \mathrm{w} / \mathrm{v} 350 \mathrm{kDa}$ poly(methyl methacrylate) (PMMA) solution in toluene for $30 \mathrm{~s}$ at $3000 \mathrm{rpm}$. To remove residual solvent, the wafer was baked at $120^{\circ} \mathrm{C}$ for $10 \mathrm{~min}$. NIL was carried out using a Peltier temperature-controlled (Julabo FP 50) HP Specac NIL setup at 200 ${ }^{\circ} \mathrm{C}$ set to 1 ton for $10 \mathrm{~min}$. As imprint master a 4 in. $1 \mathrm{H}, 1 \mathrm{H}, 2 \mathrm{H}, 2 \mathrm{H}$ perfluorodecyltrichlorosilane (AB111155, ABCR)-coated Si-wafer with $241 \mathrm{~cm}^{2}$ patterns of 10 to $25 \mu \mathrm{m}$ wide ridges separated by $5 \mu \mathrm{m}$ wide and $\sim 0.5 \mu \mathrm{m}$ deep trenches was used. In detail, the patterned imprint master was brought into contact with the spin-coated PMMA layer on the Borofloat wafer, cushioned with Kunze heat-conducting cushioning foil (KU-TXE100) on one side and 4 layers of aluminum foil on the other side, and sealed with aluminum foil. This stack was heated to 200 ${ }^{\circ} \mathrm{C}$, without applying pressure; then the pressure was carefully increased to the equivalent of 1 ton, and these conditions were kept constant for $10 \mathrm{~min}$. Subsequently, the heating was switched off, while keeping the pressure constant. Upon reaching $100{ }^{\circ} \mathrm{C}$, the pressure was left to decrease simultaneously with the temperature. Upon reaching $80{ }^{\circ} \mathrm{C}$ and complete pressure relief, the stack was removed from the NIL setup and disassembled and residual layer removal was carried out using an SPI Supplies Plasmaprep II oxygen-plasma cleaner. The progress of residual layer removal was monitored for each of the $1 \mathrm{~cm}^{2}$ patterns individually using an Olympus $\mathrm{BH} 2$ light microscope in transmission mode with a halogen lamp as light source. Upon completion of removing the residual layer (with only $5 \mu \mathrm{m}$ wide ridges of PMMA remaining), the substrates were silanized by overnight chemical vapor deposition of $N$-[3-(trimethoxysilyl)propyl]ethylenediamine in vacuo. To remove any excess silane, the samples were rinsed thoroughly with ethanol. The resulting amine-terminated line patterns were reacted with phenyl diisothiocyanate (ITC). To this end, the samples were immersed in a $0.04 \mathrm{M}$ solution of ITC in ethanol for $2 \mathrm{~h}$ at $50{ }^{\circ} \mathrm{C}$ under argon. After the reaction, the samples were rinsed with ethanol and dried in a flow of $\mathrm{N}_{2}$. The ITCterminated line patterns were then functionalized with $N_{\alpha}, N_{\alpha}$ bis(carboxymethyl)-L-lysine (NTA- $\left.\mathrm{NH}_{2}\right)$. To this end, the samples were incubated in a $1 \mathrm{mM}$ solution of NTA- $\mathrm{NH}_{2}$ in water at $50{ }^{\circ} \mathrm{C}$ for $2 \mathrm{~h}$ under argon. All remaining PMMA was then stripped from the Borofloat substrates by 30 min sonication in $1 \mathrm{~L}$ of acetone, rinsing with acetone, and drying with $\mathrm{N}_{2}$. Subsequently, the unfunctionalized ( $5 \mu \mathrm{m}$ wide) lines were functionalized with a solution of $100 \mu \mathrm{L}$ of [methoxy(polyethyleneoxy)propyl] trimethoxysilane (PEG)-silane $(\mathrm{AB} 111226, \mathrm{ABCR})$ in $60 \mathrm{~mL}$ of dry toluene by leaving the samples to react overnight at room temperature under argon. After washing the samples with toluene they were dried under a flow of $\mathrm{N}_{2}$. The resulting NTA/PEG line patterns could be stored under $\mathrm{N}_{2}$ for a maximum of 4 weeks prior to use.

Protein Immobilization on (Patterned) Substrates. For protein immobilization NTA-terminated (patterned) layers were incubated, if necessary, with a $1 \mathrm{mM} \mathrm{NiCl} 2 \cdot 6 \mathrm{H}_{2} \mathrm{O}$ solution in water for $30 \mathrm{~min}$, and the substrates were rinsed briefly with water. For the subsequent immobilization of proteins, substrates were incubated with the appropriate protein solution (of $1 \mu \mathrm{M}$ concentration, unless stated otherwise) for $1 \mathrm{~h}$ (unless stated otherwise) in a humidity chamber. Protein solutions were then removed with a pipet and retained for further use, and samples washed on an orbital shaker $(80 \mathrm{rpm})$ in the appropriate buffers overnight (unless stated otherwise). Samples were then rinsed with the appropriate buffer and subsequently with water and imaged using an Olympus IX70 inverted fluorescence microscope; see below.

Thermodynamic Multivalency Model for Fitting SPR Titration Data. We adapted a model previously reported in the literature ${ }^{41,63,67}$ in order to predict and determine the thermodynamic stability parameters of the protein-surface complexes to fit the SPR data obtained experimentally. We here consider each $\mathrm{His}_{6}$-tag to behave as a single motif, binding to three surface-bound $\mathrm{Ni}^{2+}$ :NTA (NiNTA in formulas) units simultaneously, with an effective concentration value $\left(C_{\text {eff }}\right)$ controlling the binding of consecutive $\mathrm{His}_{6}$-tags once the first one is bound. The model is summarized in the Supporting Information (eqs S1-S5) and solved using a spreadsheet approach. $^{84}$

Molecular Dynamics. Molecular Langevin dynamics were performed using the NAMD program ${ }^{85}$ together with the CHARMM force field. ${ }^{86}$ Short-range nonbonded interactions were computed up to $1.2 \mathrm{~nm}$ distance. Ewald summation was used to calculate the electrostatic interactions, and a 2 fs time step was used for dynamics by constraining covalent bonds to hydrogen. The coordinates for TagRFP were taken from the PDB (ID: $3 \mathrm{M} 22$ ). The $\mathrm{VMD}^{87}$ mutate residue plugin was used to change residues Cys114, Cys222, and Ser128 to serine and cysteine, respectively. In order to run Molecular Dynamics simulations on the TagRFP-His ${ }_{6}-\mathrm{Ni}^{2+}$ :NTA interface, it was necessary to parametrize the chromophore found in the center of the protein, the maleimide linker used to attach the third His tag to the protein, and the $\mathrm{Ni}^{2+}$ :NTA molecule used in the SAM. Parametrization was carried out using the Paramchem ${ }^{88}$ Web tool, and the partial charges were mapped onto the CHARMM force field. ${ }^{89}$

A $\mathrm{Au}(111)$ slab of surface area $2800 \AA^{2}$ was cut from bulk gold metal, and $384 \mathrm{Ni}^{2+}$ :NTA molecules were placed on one face. The SAM model was encased in a large water box with dimensions $20 \times 20$ $\times 10 \mathrm{~nm}$, and periodic boundary conditions were applied. The SAM (31 872 atoms) was first relaxed using 6000 steps of steepest descent minimization and then allowed to equilibrate to a stable roomtemperature structure over $1 \mathrm{~ns}$ of molecular dynamics and subjected to a further $7 \mathrm{~ns}$ of dynamics with a constant-density monolayer forming within $5 \mathrm{~ns}$. The sulfur atoms were then weakly constrained at these equilibrated surface-bound positions to simulate the gold-sulfur bond that is formed in the experiments. A similar protocol was used to model the mixed SAM, with clusters of 5-10 $\mathrm{Ni}^{2+}$ :NTA molecules surrounded by nonfunctionalized acid-terminated chains. Simulation input files and calculated SAM structures are available on request from D.T. To study the protein-SAM interactions, the TagRFP protein was 
placed near the SAM in two different orientations (end-on and sideon; see Chart 1) with a varying number of bound histidine residues, and the Avogadro program ${ }^{90}$ was used to position the histidine residues near the $\mathrm{Ni}^{2+}$ ions in the SAM in positions where a complex might form. The system was equilibrated with gradually loosening positional constraints on the histidine side chains for 8 ns. Free dynamics simulations were then run on the system for $20 \mathrm{~ns}$, sampling every $100 \mathrm{ps}$. Image generation and Tcl script-based trajectory analysis were performed using the VMD program. ${ }^{8}$

For the steered MD simulations, two configurations were taken from the equilibrium $\mathrm{MD}$ simulations. They were chosen to have the same number of adsorbed histidine residues in order to be able to compare like with like as much as possible. For both configurations, SMD simulations were performed using GROMACS 5.1.191 and the CHARMM force field to pull the protein a distance of $110 \AA$ over a time of $7 \mathrm{~ns}$ from the SAM. Fifty-eight configurations were then taken from these trajectories and subjected to $10 \mathrm{~ns}$ of umbrella sampling simulations. The PMF profile was calculated over the sampled windows using the gmx_wham command in GROMACS.

\section{ASSOCIATED CONTENT}

\section{(S Supporting Information}

The Supporting Information is available free of charge on the ACS Publications website at DOI: 10.1021/acsnano.7b03717.

Schemes S1, S2; Tables S1-S7; Figures S1-S15; and eqs S1-S5 (PDF)

\section{AUTHOR INFORMATION}

\section{Corresponding Authors}

*E-mail: damien.thompson@ul.ie.

*E-mail: j.huskens@utwente.nl.

*E-mail: v.subramaniam@vu.nl.

*E-mail: p.jonkheijm@utwente.nl.

\section{ORCID}

Jurriaan Huskens: 0000-0002-4596-9179

Vinod Subramaniam: 0000-0001-6712-7266

Pascal Jonkheijm: 0000-0001-6271-0049

\section{Author Contributions}

D.W. and P.J. conceived the project. D.W. engineered and together with E.T. produced the protein mutants. D.W., V.S., and P.J. analyzed the protein constructs. D.W. and J.C.-D. performed (patterned) protein immobilization studies. D.W., J.C.-D., and E.T. performed SPR binding studies. J.C.-D. applied the multivalent model, which was supervised by J.H. J.P. designed and together with D.W. performed fluorescence lifetime measurements, and J.P, D.W., and C.B. analyzed the data. C.B. and V.S. supervised polarization anisotropy setups. IRRAS measurements were done by D.W. and J.C.-D. S.O'M., P.-A.C., and D.T. performed and analyzed computer simulations, which was supervised by D.T. D.W., J.C.-D., J.P., S.O'M., P.-A.C., D.T., J.H., V.S., and P.J. were involved in the analysis of the data. D.W. and J.C.-D. prepared the manuscript. P.J. wrote the manuscript. P.J. supervised the entire project. All authors have given approval to the final version of the manuscript.

\section{Author Contributions}

${ }^{\#}$ D. Wasserberg and J. Cabanas-Danés contributed equally.

\section{Notes}

The authors declare no competing financial interest.

\section{ACKNOWLEDGMENTS}

D.W. thanks the German Academic Exchange Service for financial support under postdoctoral research grant $\mathrm{D} / 08$ /
46093. Work by J.C.-D., E.T., and P.J. was funded by Project P2.02 OAcontrol of the research program of the BioMedical Materials Institute, cofunded by the Dutch Ministry of Economic Affairs. J.P. and V.S. acknowledge support from Stichting Technische Wetenschappen (STW) under the nanoscopy program (project no. 12149). The work by D.W. and P.J. was cofunded by Starting ERC Grant (259183 Sumoman). D.T. acknowledges financial support from the European Union's Seventh Framework Programme (FP7/ 2007-2013) under grant number 604530-2 (CellulosomePlus) and thanks Science Foundation Ireland (SFI) for financial support under Grant Number 15/CDA/3491 and for provision of computing resources at the SFI/Higher Education Authority Irish Centre for High-End Computing (ICHEC). The authors thank Dr. M. Koay from the University of Twente for discussions and comments.

\section{REFERENCES}

(1) Dufva, M.; Christensen, C. B. V. Diagnostic and Analytical Applications of Protein Microarrays. Expert Rev. Proteomics 2005, 2, $41-48$.

(2) Terstappen, G. C.; Schluepen, C.; Raggiaschi, R.; Gaviraghi, G. Target Deconvolution Strategies in Drug Discovery. Nat. Rev. Drug Discovery 2007, 6, 891-903.

(3) Weinrich, D.; Jonkheijm, P.; Niemeyer, C. M.; Waldmann, H. Applications of Protein Biochips in Biomedical and Biotechnological Research. Angew. Chem., Int. Ed. 2009, 48, 7744-7751.

(4) Manoli, K.; Magliulo, M.; Mulla, M. Y.; Singh, M.; Sabbatini, L.; Palazzo, G.; Torsi, L. Printable Bioelectronics to Investigate Functional Biological Interfaces. Angew. Chem., Int. Ed. 2015, 54, 12562-12576.

(5) Mitchell, A. C.; Briquez, P. S.; Hubbell, J. A.; Cochran, J. R. Engineering Growth Factors for Regenerative Medicine Applications. Acta Biomater. 2016, 30, 1-12.

(6) Wei, Q.; Becherer, T.; Angioletti-Uberti, S.; Dzubiella, J.; Wischke, C.; Neffe, A. T.; Lendlein, A.; Ballauff, M.; Haag, R. Protein Interactions with Polymer Coatings and Biomaterials. Angew. Chem., Int. Ed. 2014, 53, 8004-8031.

(7) Tong, Z.; Solanki, A.; Hamilos, A.; Levy, O.; Wen, K.; Yin, X.; Karp, J. M. Application of Biomaterials to Advance Induced Pluripotent Stem Cell Research and Therapy. EMBO J. 2015, 34, 987-1008.

(8) Gupta, A.; Patel, V. K.; Kant, R.; Bhattacharya, S. Surface Modification Strategies for Fabrication of Nano-biodevices: A Critical Review. RAA 2016, 4, 166-191.

(9) Mendes, P. M. Stimuli-Responsive Surfaces for Bio-Applications. Chem. Soc. Rev. 2008, 37, 2512-2529.

(10) Wong, L. S.; Khan, F.; Micklefield, J. Selective Covalent Protein Immobilization: Strategies and Applications. Chem. Rev. 2009, 109, 4025-4053.

(11) Rusmini, F.; Zhong, Z.; Feijen, J. Protein Immobilization Strategies for Protein Biochips. Biomacromolecules 2007, 8, 17751789.

(12) Jonkheijm, P.; Weinrich, D.; Schroeder, H.; Niemeyer, C. M.; Waldmann, H. Chemical Strategies for Generating Protein Biochips. Angew. Chem., Int. Ed. 2008, 47, 9618-9647.

(13) Hackenberger, C. P. R.; Schwarzer, D. Chemoselective Ligation and Modification Strategies for Peptides and Proteins. Angew. Chem., Int. Ed. 2008, 47, 10030-10074.

(14) Chen, Y.-X.; Triola, G.; Waldmann, H. Bioorthogonal Chemistry for Site-Specific Labeling and Surface Immobilization of Proteins. Acc. Chem. Res. 2011, 44, 762-773.

(15) Reyna, K. V. L; Qing, L. Bioorthogonal Chemistry: Recent Progress and Future Directions. Chem. Commun. 2010, 46 (46), $1589-1600$

(16) Sletten, E. M.; Bertozzi, C. R. Bioorthogonal Chemistry: Fishing for Selectivity in a Sea of Functionality. Angew. Chem., Int. Ed. 2009, $48,2-27$. 
(17) Duckworth, B. P.; Xu, J.; Taton, T. A.; Guo, A.; Distefano, M. D. Site-Specific, Covalent Attachment of Proteins to a Solid Surface. Bioconjugate Chem. 2006, 17, 967-974.

(18) Govindaraju, T.; Jonkheijm, P.; Gogolin, L.; Schroeder, H.; Becker, C. F. W.; Niemeyer, C. M.; Waldmann, H. Surface Immobilization of Biomolecules by Click Sulfonamide Reaction. Chem. Commun. 2008, 32, 3723-3725.

(19) Christman, K. L.; Broyer, R. M.; Tolstyka, Z. P.; Maynard, H. D. Site-Specific Protein Immobilization Through N-Terminal Oxime Linkages. J. Mater. Chem. 2007, 17, 2021-2027.

(20) Hodneland, C. D.; Lee, Y.-S.; Min, D.-H.; Mrksich, M. Selective Immobilization of Proteins to Self-Assembled Monolayers Presenting Active Site-Directed Capture Ligands. Proc. Natl. Acad. Sci. U. S. A. 2002, 99, 5048-5052.

(21) Wasserberg, D.; Nicosia, C.; Tromp, E. E.; Subramaniam, V.; Huskens, J.; Jonkheijm, P. Oriented Protein Immobilization Using Covalent and Non-Covalent Chemistry on a Thiol-Reactive SelfReporting Surface. J. Am. Chem. Soc. 2013, 135, 3104-3111.

(22) Becker, C. F. W.; Wacker, R.; Bouschen, W.; Seidel, R.; Kolaric, B.; Lang, P.; Schroeder, H.; Mueller, O.; Niemeyer, C. M.; Spengler, B.; Goody, R. S.; Engelhard, M. Direct Readout of Protein-Protein Interactions by Mass Spectrometry from Protein-DNA Microarrays. Angew. Chem., Int. Ed. 2005, 44, 7635-7639.

(23) Kwon, Y.; Coleman, M. A.; Camarero, J. A. Selective Immobilization of Proteins onto Solid Supports Through SplitIntein-Mediated Protein Trans-Splicing. Angew. Chem., Int. Ed. 2006, $45,1726-1729$.

(24) Hwang, I.; Baek, K.; Jung, M.; Kim, Y.; Park, K. M.; Lee, D.-W.; Selvapalam, N.; Kim, K. Noncovalent Immobilization of Proteins on a Solid Surface by Cucurbit[7]uril-Ferrocenemethylammonium Pair, a Potential Replacement of Biotin-Avidin Pair. J. Am. Chem. Soc. 2007, 129, 4170-4171.

(25) Grunwald, C.; Schulze, K.; Reichel, A.; Weiss, V. U.; Blaas, D.; Piehler, J.; Wiesmuller, K.-H.; Tampé, R. In Situ Assembly of Macromolecular Complexes Triggered by Light. Proc. Natl. Acad. Sci. U. S. A. 2010, 107, 6146-6151.

(26) Wan, P.; Wang, Y.; Jiang, Y.; Xu, H.; Zhang, X. Fabrication of Reactivated Biointerface for Dual-Controlled Reversible Immobilization of Cytochrome c. Adv. Mater. 2009, 21, 4362-4365.

(27) Yang, L.; Gómez-Casado, A.; Young, J. F.; Nguyen, H. D.; Cabanas-Danés, J.; Huskens, J.; Brunsveld, L.; Jonkheijm, P. Reversible and Oriented Immobilization of Ferrocene-Modified Proteins. J. Am. Chem. Soc. 2012, 134, 19199-19206.

(28) Gutiérrez Sánchez, C.; Su, Q.; Schönherr, H.; Grininger, M.; Nöll, G. Multi-Ligand-Binding Flavoprotein Dodecin as a Key Element for Reversible Surface Modification in Nano-Biotechnology. ACS Nano 2015, 9, 3491-3500.

(29) Muller, W.; Ringsdorf, H.; Rump, E.; Wildburg, G.; Zhang, X.; Angermaier, L.; Knoll, W.; Liley, M.; Spinke, J. Attempts to Mimic Docking Processes of the Immune System: Recognition-Induced Formation of Protein Multilayers. Science 1993, 262, 1706-1708.

(30) Mrksich, M.; Grunwell, J. R.; Whitesides, G. M. Biospecific Adsorption of Carbonic Anhydrase to Self-Assembled Monolayers of Alkanethiolates That Present Benzenesulfonamide Groups on Gold. J. Am. Chem. Soc. 1995, 117, 12009-12010.

(31) González-Campo, A.; Eker, B.; Gardeniers, H. J. G. E.; Huskens, J.; Jonkheijm, P. A Supramolecular Approach to Enzyme Immobilization in Micro-Channels. Small 2012, 8, 3531-3537.

(32) Wood, L. L.; Cheng, S. S.; Edmiston, P. L.; Saavedra, S. S. Molecular Orientation Distributions in Protein Films 2. Site-Directed Immobilization of Yeast Cytochrome $\mathrm{c}$ on Thiol-Capped, SelfAssembled Monolayers. J. Am. Chem. Soc. 1997, 119, 571-576.

(33) Edminston, P. L.; Saavedra, S. S. Molecular Orientation Distributions in Protein Films. 4. A Multilayer Composed of Yeast Cytochrome c Bound through an Intermediate Streptavidin Layer to a Planar Supported Phospholipid Bilayer. J. Am. Chem. Soc. 1998, 120, $1665-1671$.

(34) Sanavio, B.; Scaini, D.; Grunwald, C.; Legname, G.; Scoles, G.; Casalis, L. Oriented Immobilization of Prion Protein Demonstrated via Precise Interfacial Nanostructure Measurements. ACS Nano 2010, 4, 6607-6616.

(35) Escalante, M.; Zhao, Y.; Ludden, M. J. W.; Vermeij, R.; Olsen, J. D.; Berenschot, E.; Hunter, C. N.; Huskens, J.; Subramaniam, V.; Otto, C. Nanometer Arrays of Functional Light Harvesting Antenna Complexes by Nanoimprint Lithography and Host-Guest Interactions. J. Am. Chem. Soc. 2008, 130, 8892-8893.

(36) Escalante, M.; Lenferink, A.; Zhao, Y.; Tas, N.; Huskens, J.; Hunter, C. N.; Subramaniam, V.; Otto, C. Long-Range Energy Propagation in Nanometer Arrays of Light Harvesting Antenna Complexes. Nano Lett. 2010, 10, 1450-1457.

(37) Dorn, I. T.; Eschrich, R.; Seemueller, E.; Guckenberger, R.; Tampé, R. High-Resolution AFM-Imaging and Mechanistic Analysis of the 20S Proteasome. J. Mol. Biol. 1999, 288, 1027-1036.

(38) Hutschenreiter, S.; Tinazli, A.; Model, K.; Tampé, R. TwoSubstrate Association with the 20S Proteasome at Single-Molecule Level. EMBO J. 2004, 23, 2488-2497.

(39) Mammen, M.; Choi, S.-K.; Whitesides, G. M. Polyvalent Interactions in Biological Systems: Implications for Design and Use of Multivalent Ligands and Inhibitors. Angew. Chem., Int. Ed. 1998, 37, 2754-2794.

(40) Mulder, A.; Huskens, J.; Reinhoudt, D. N. Multivalency in Supramolecular Chemistry and Nanofabrication. Org. Biomol. Chem. 2004, 2, 3409-3424.

(41) De, M.; Rana, S.; Rotello, V. M. Nickel-Ion-Mediated Control of the Stoichiometry of His-Tagged Protein/Nanoparticle Interactions. Macromol. Biosci. 2009, 9, 174-178.

(42) Schmitt, J.; Hess, H.; Stunnenberg, H. G. Affinity Purification of Histidine-Tagged Proteins. Mol. Biol. Rep. 1993, 18, 223-230.

(43) Hochuli, E.; Dobeli, H.; Schacher, A. New Metal Chelate Adsorbent Selective for Proteins and Peptides Containing Neighbouring Histidine Residues. J. Chromatogr. A 1987, 411, 177-184.

(44) Young, C. L.; Britton, Z. T.; Robinson, A. S. Recombinant Protein Expression and Purification: A Comprehensive Review of Affinity Tags and Microbial Applications. Biotechnol. J. 2012, 7, 620634.

(45) Goodman, R. P.; Erben, C. M.; Malo, J.; Ho, W. M.; McKee, M. L.; Kapanidis, A. N.; Turberfield, A. J. A Facile Method for Reversibly Linking a Recombinant Protein to DNA. ChemBioChem 2009, 10, $1551-1557$

(46) Nieba, L.; Nieba-Axmann, S. E.; Persson, A.; Hämäläinen, M.; Edebratt, F.; Hansson, A.; Lidholm, J.; Magnusson, K.; Karlsson, Å. F.; Plückthun, A. BIACORE Analysis of Histidine-Tagged Proteins Using a Chelating NTA Sensor Chip. Anal. Biochem. 1997, 252, 217-228.

(47) André, T.; Reichel, A.; Wiesmueller, K.-H.; Tampé, R.; Piehler, J.; Brock, R. Selectivity of Competitive Multivalent Interactions at Interfaces. ChemBioChem 2009, 10, 1878-1887.

(48) Alonso, J. M.; Reichel, A.; Piehler, J.; del Campo, A. Photopatterned Surfaces for Site-Specific and Functional Immobilization of Proteins. Langmuir 2007, 24, 448.

(49) Zhu, H.; Bilgin, M.; Bangham, R.; Hall, D.; Casamayor, A.; Bertone, P.; Lan, N.; Jansen, R.; Bidlingmaier, S.; Houfek, T.; Mitchell, T.; Miller, P.; Dean, R. A.; Gerstein, M.; Snyder, M. Global Analysis of Protein Activities Using Proteome Chips. Science 2001, 293, 21012105.

(50) Selmi, D. N.; Adamson, R. J.; Attrill, H.; Goddard, A. D.; Gilbert, R. J. C.; Watts, A.; Turberfield, A. J. 20. DNA-Templated Protein Arrays for Single-Molecule Imaging. Nano Lett. 2011, 11, $657-660$.

(51) Marin, V. L.; Bayburt, T. H.; Sligar, S. G.; Mrksich, M. Functional Assays of Membrane-Bound Proteins with SAMDI-TOF Mass Spectrometry. Angew. Chem., Int. Ed. 2007, 46, 8796-8798.

(52) Maury, P.; Escalante-Marun, M.; Péter, M.; Reinhoudt, D. N.; Subramaniam, V.; Huskens, J. Creating Nanopatterns of His-Tagged Proteins on Surfaces by Nanoimprint Lithography Using Specific NiNTA-Histidine Interactions. Small 2007, 3, 1584-1592.

(53) Turchanin, A.; Tinazli, A.; El-Desawy, M.; Großmann, H.; Schnietz, M.; Solak, H. H.; Tampé, R.; Gölzhäuser, A. Molecular SelfAssembly, Chemical Lithography, and Biochemical Tweezers: a Path 
for the Fabrication of Functional Nanometer-Scale Protein Arrays. Adv. Mater. 2008, 20, 471-477.

(54) Hansen, J. A.; Sumbayev, V. V.; Gothelf, K. V. An Electrochemical Sensor Based on the Human Estrogen Receptor Ligand Binding Domain. Nano Lett. 2007, 7, 2831-2834.

(55) Cabanas-Danés, J.; Dooms Rodrigues, E.; Landman, E.; van Weerd, J.; van Blitterswijk, C. A.; Verrips, T.; Huskens, J.; Karperien, M.; Jonkheijm, P. A Supramolecular Host-Guest Carrier System for Growth Factors Employing VHH Fragments. J. Am. Chem. Soc. 2014, 136, 12675-12681.

(56) Lata, S.; Reichel, A.; Brock, R.; Tampé, R.; Piehler, J. HighAffinity Adaptors for Switchable Recognition of Histidine-Tagged Proteins. J. Am. Chem. Soc. 2005, 127, 10205-10215.

(57) Lata, S.; Gavutis, M.; Tampé, R.; Piehler, J. Specific and Stable Fluorescence Labeling of Histidine-Tagged Proteins for Dissecting Multi-Protein Complex Formation. J. Am. Chem. Soc. 2006, 128, 2365-2372.

(58) Valiokas, R.; Klenkar, G.; Tinazli, A.; Reichel, A.; Tampe, R.; Piehler, J.; Liedberg, B. Self-Assembled Monolayers Containing Terminal Mono-, Bis-, and Tris-nitrilotriacetic Acid Groups: Characterization and Application. Langmuir 2008, 24, 4959-4967.

(59) Lata, S.; Piehler, J. Stable and Functional Immobilization of Histidine-Tagged Proteins via Multivalent Chelator Headgroups on a Molecular Poly(ethylene glycol) Brush. Anal. Chem. 2005, 77, 10961105

(60) Tinazli, A.; Tang, J.; Valiokas, R.; Picuric, S.; Lata, S.; Piehler, J.; Liedber, B.; Tampé, R. High-Affinity Chelator Thiols for Switchable and Oriented Immobilization of Histidine-Tagged Proteins: A Generic Platform for Protein Chip Technologies. Chem. - Eur. J. 2005, 11, 5249-5259.

(61) Huang, Z.; Park, J. I.; Watson, D. S.; Hwang, P.; Szoka, F. C., Jr. Facile Synthesis of Multivalent Nitrilotriacetic Acid (NTA) and NTA Conjugates for Analytical and Drug Delivery Applications. Bioconjugate Chem. 2006, 17, 1592-1600.

(62) Huang, Z.; Hwang, P.; Watson, D. S.; Cao, L.; Szoka, F. C., Jr. Tris-Nitrilotriacetic Acids of Subnanomolar Affinity Toward Hexahistidine Tagged Molecules. Bioconjugate Chem. 2009, 20, 16671672.

(63) Ludden, M. J. W.; Mulder, A.; Schulze, K.; Subramaniam, V.; Tampé, R.; Huskens, J. Anchoring of Histidine-Tagged Proteins to Molecular Printboards: Self-Assembly, Thermodynamic Modeling, and Patterning. Chem. - Eur. J. 2008, 14, 2044-2051.

(64) Zhen, G.; Falconnet, D.; Kuennemann, E.; Vörös, J.; Spencer, N. D.; Textor, M.; Zürcher, S. Nitrilotriacetic Acid Functionalized Graft Copolymers: A Polymeric Interface for Selective and Reversible Binding of Histidine-Tagged Proteins. Adv. Funct. Mater. 2006, 16, 243-251.

(65) Knezevic, J.; Langer, A.; Hampel, P. A.; Kaiser, W.; Strasser, R.; Rant, U. Quantitation of Affinity, Avidity, and Binding Kinetics of Protein Analytes with a Dynamically Switchable Biosurface. J. Am. Chem. Soc. 2012, 134, 15225-15228.

(66) Merzlyak, E. M.; Goedhart, J.; Shcherbo, D.; Bulina, M. E.; Shcheglov, A. S.; Fradkov, A. F.; Gaintzeva, A.; Lukyanov, K. A.; Lukyanov, S.; Gadella, T. W.; Chudakov, D. M. Bright Monomeric Red Fluorescent Protein with an Extended Fluorescence Lifetime. Nat. Methods 2007, 4, 555-557.

(67) Huskens, J.; Mulder, A.; Auletta, T.; Nijhuis, C. A.; Ludden, M. J.; Reinhoudt, D. N. A Model for Describing the Thermodynamics of Multivalent Host-Guest Interactions at Interfaces. J. Am. Chem. Soc. 2004, 126, 6784-6797.

(68) Mulder, A.; Auletta, T.; Sartori, A.; Del Ciotto, S.; Casnati, A.; Ungaro, R.; Huskens, J.; Reinhoudt, D. N. Divalent Binding of a Bis(adamantyl)-Functionalized Calix[4] arene to $\beta$-Cyclodextrin-Based Hosts: An Experimental and Theoretical Study on Multivalent Binding in Solution and at Self-Assembled Monolayers. J. Am. Chem. Soc. 2004, $126,6627-6636$.

(69) Subach, O. M.; Malashkevich, V. N.; Zencheck, W. D.; Morozova, K. S.; Piatkevich, K. D.; Almo, S. C.; Verkhusha, V. V. Structural Characterization of Acylimine-Containing Blue and Red
Chromophores in mTagBFP and TagRFP Fluorescent Proteins. Chem. Biol. 2010, 17, 333-341.

(70) Frey, B. L.; Corn, R. M. Covalent Attachment and Derivatization of Poly(L-lysine) Monolayers on Gold Surfaces as Characterized by Polarization-Modulation FT-IR Spectroscopy. Anal. Chem. 1996, 68, 3187-3193.

(71) Goormaghtigh, E.; Cabiaux, V.; Ruysschaert, J. M. Secondary Structure and Dosage of Soluble and Membrane-Proteins by Attenuated Total Reflection Fourier-Transform Infrared-Spectroscopy on Hydrated Films. Eur. J. Biochem. 1990, 193, 409-420.

(72) Chen, C.-W.; Liu, H.-L.; Lin, J.-C.; Ho, Y. Molecular Dynamics Simulations of Metal Ion Binding to the His-tag Motif. J. Chin. Chem. Soc. 2005, 52, 1281-1290.

(73) Watly, J.; Simonovsky, E.; Wieczorek, R.; Barbosa, N.; Miller, Y.; Kozlowski, H. Insight into the Coordination and the Binding Sites of $\mathrm{Cu}^{2+}$ by the Histidyl-6-Tag using Experimental and Computational Tools. Inorg. Chem. 2014, 53, 6675-6683.

(74) Zhang, Y.; Lai, C.-T.; Hinds, B. J.; Schatz, G. C. Kinetic Master Equation Modeling of an Artificial Protein Pump. J. Phys. Chem. C 2016, 120, 14495-14501.

(75) Nifosì, R; Tozzini, V. Molecular Dynamics Simulations of Enhanced Green Fluorescent Proteins: Effects of F64L, S65T and T203Y Mutations on the Ground-State Proton Equilibria. Proteins: Struct., Funct., Genet. 2003, 51, 378-389.

(76) Mitchell, F. L.; Frank, F.; Marks, G. E.; Suzuki, M.; Douglas, K. T.; Bryce, R. A. Molecular Dynamics Study of Chemically Engineered Green Fluorescent Protein Mutants: Comparison of Intramolecular Fluorescence Resonance Energy Transfer Rate. Proteins: Struct., Funct., Genet. 2009, 75, 28-39.

(77) Demachy, I.; Ridard, J.; Laguitton-Pasquier, H.; Durnerin, E.; Vallverdu, G.; Archirel, P.; Lévy, B. Cyan Fluorescent Protein: Molecular Dynamics, Simulations, and Electronic Absorption Spectrum. J. Phys. Chem. B 2005, 109, 24121-24133.

(78) Nishiyama, K.; Watanabe, T.; Hoshino, T.; Ohdomari, I. Analysis of Interactions between Green Fluorescent Protein and Silicon Substrates Using Molecular Dynamics Simulations. Jpn. J. Appl. Phys. 2005, 44, 8210-8215.

(79) Khassanov, A.; Steinrück, H.-G.; Schmaltz, T.; Magerl, A.; Halik, M. Structural Investigations of Self-Assembled Monolayers for Organic Electronics: Results from X-ray Reflectivity. Acc. Chem. Res. 2015, 48, 1901-1908.

(80) Yang, Z. Y.; Zhao, Y. P. QM/MM and Classical Molecular Dynamics Simulation of Histidine-Tagged Peptide Immobilization on Nickel Surface. Mater. Sci. Eng., A 2006, 423, 84-91.

(81) Love, J. C.; Estroff, L. A.; Kriebel, J. K.; Nuzzo, R. G.; Whitesides, G. M. Self-Assembled Monolayers of Thiolates on Metals as a Form of Nanotechnology. Chem. Rev. 2005, 105, 1103-1170.

(82) Chandler, D. Interfaces and the Driving Force of Hydrophobic Assembly. Nature 2005, 437, 640-647.

(83) Höök, F.; Rodahl, M.; Kasemo, B.; Brezezinski, P. Structural Changes in Hemoglobin During Adsorption to Solid Surfaces: Effects of $\mathrm{pH}$, Ionic Strength, and Ligand Binding. Proc. Natl. Acad. Sci. U. S. A. 1998, 95, 12271-12276.

(84) Huskens, J.; Van Bekkum, H.; Peters, J. A. A Convenient Spreadsheet Approach to the Calculation of Stability Constants and the Simulation of Kinetics. Comput. Chem. 1995, 19, 409-416.

(85) Phillips, J. C.; Braun, R.; Wang, W.; Gumbart, J.; Tajkhorshid, E.; Villa, E.; Chipot, C.; Skeel, R. D.; Kalé, L.; Schulten, K. Scalable Molecular Dynamics with NAMD. J. Comput. Chem. 2005, 26, 17811802.

(86) Vanommeslaeghe, K.; Hatcher, E.; Acharya, C.; Kundu, S.; Zhong, S.; Shim, J.; Darian, E.; Guvench, O.; Lopes, P.; Vorobyov, I.; Mackerell, A. D. CHARMM General Force Field: A Force Field for Drug-Like Molecules Compatible with the CHARMM All-Atom Additive Biological Force Fields. J. Comput. Chem. 2010, 31, 671-690.

(87) Humphrey, W.; Dalke, A.; Schulten, K. VMD: Visual Molecular Dynamics. J. Mol. Graphics 1996, 14, 33-38.

(88) CGenFF Home. Available at https://cgenff.paramchem.org/. Accessed: Sep 21, 2016. 
(89) Vanommeslaeghe, K.; Raman, E. P.; MacKerell, A. D. Automation of the CHARMM General Force Field (CGenFF) II: Assignment of Bonded Parameters and Partial Atomic Charges. J. Chem. Inf. Model. 2012, 52, 3155-3168.

(90) Hanwell, M. D.; Curtis, D. E.; Lonie, D. C.; Vandermeersch, T.; Zurek, E.; Hutchison, G. R. Avogadro: An Advanced Semantic Chemical Editor, Visualization, and Analysis Platform. J. Cheminf. 2012, 4, 17.

(91) Abraham, M. J.; Murtolar, T.; Schulz, R.; Pall, S.; Smith, J. C.; Hess, B.; Lindahl, E. GROMACS: High Performace Molecular Simulations Through Multi-Level Parallelism From Laptops to Supercomputers. SoftwareX 2015, 1-2, 19-25. 